Linköping Studies in Science and Technology

Dissertation No 1885

\title{
On decoration of biomolecular scaffolds with a conjugated polyelectrolyte
}

\author{
Anders Fredrik Elfwing
}

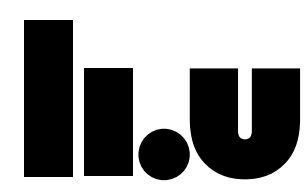

LINKÖPING UNIVERSITY

Biomolecular and Organic Electronics

Department of Physics, Chemistry, and Biology

Linköping University, Sweden

Linköping 2017 
On decoration of biomolecular scaffolds with a conjugated polyelectrolyte Anders Elfwing

During the course of the research underlying this thesis, Anders Elfwing was enrolled in Forum Scientium, a multidisciplinary doctoral program at Linköping University, Sweden.

Linköping Studies in Science and Technology. Dissertations. No. 1885

(C2017 Anders Elfwing unless otherwise noted

Printed by LiU-Tryck, Linköping, Sweden, 2017

ISBN 978-91-7685-437-2 ISSN: 0345-7524

Electronic publication: http://www.ep.liu.se 
"What I cannot create, I do not understand"

Richard Feynman 


\begin{abstract}
Biotemplating is the art of using a biological structure as a scaffold which is decorated with a functional material. In this fashion the structures will gain new functionalities and biotemplating offers a simple route of mass-producing mesoscopic material with new interesting properties. Biological structures are abundant and come in a great variety of elaborate and due to their natural origin they could be more suitable for interaction with biological systems than wholly synthetic materials. Conducting polymers are a novel class of material which was developed just 40 years ago and are well suited for interaction with biological material due to their organic composition. Furthermore the electronic properties of the conducting polymers can be tuned giving rise to dynamic control of the behavior of the material. Self-assembly processes are interesting since they do not require complicated or energy demanding processing conditions. This is particularly important as most biological materials are unstable at elevated temperatures or harsh environments. The main aim of this thesis is to show the possibility of using self-assembly to decorate a conducting polymer onto various biotemplates. Due to the intrinsic variety in charge, size and structure between the available natural scaffolds it is difficult, if not impossible, to find a universal method.
\end{abstract}

In this thesis we show how biotemplating can be used to create new hybrid materials by self-assembling a conducting polymer with biological structures based on DNA, protein, lipids and cellulose, and in this fashion create material with novel optical and electronic properties. 


\section{Populärvetenskaplig sammanfattning}

Modernistisk arkitektur bygger på att låta formen skulle följa funktionen; med andra ord ska byggnadens utseende framförallt vara avhängigt vad den ska användas till. I detta arbete har vi gjort det diametralt motsatta och låtit funktionen följa formen. Den funktion vi valt att använda är elektrisk ledningsförmåga och vi har låtit naturen ta fram formerna. I naturen finner vi en nästan oändlig mängd av intrikata former, må det vara spiraler, trådar eller bollar. Ett genomgående tema är dock att dessa strukturer sällan har någon elektrisk ledningsförmåga. För att få den funktion som vi önskar har vi använt en elektrisk ledande polymer, ett material som i sig är svårt att forma. Genom att variera de förhållanden som krävs för att den ledande polymeren ska interagera med strukturen har vi fått den ledande polymeren (funktionen) att följa strukturen (formen) och därmed skapat nya material med helt nya egenskaper. Huvudsyftet med denna avhandling är att påvisa att det med förhållandevis enkla metoder går att skapa nya material och att $\mathrm{i}$ framtiden möjligen kan använda dessa metoder för att skapa byggstenar i elektroniska komponenter.

För att förstå hur vi gått tillväga måste vi beakta att det finns en grundläggande skillnad i människans och naturens tillverkningsmetoder. Människan använder kraft, hög temperatur och farliga kemikalier för att smälta, bearbeta och sammanfoga material; processer som är ganska oekonomiska ur energisynpunkt. Där människan utgår från en större bit material och gradvis sågar, karvar och fräser tillverkar naturen på ett radikalt annorlunda sätt. Naturen bygger upp sina material från grunden där minimala byggstenar tillsammans skapar allt större och alltmer komplexa strukturer i en process som kallas självorganisation.

Ledande polymerer är elektriskt ledande material som främst är uppbyggda av organiskt material, det vill säga består av långa kedjor av framförallt kolatomer. Detta till skillnad från de flesta elektriska ledare som består av metaller, till exempel koppar. Organiska ledare upptäcktes på 1970-talet och belönades med Nobelpriset i fysik år 2000. Sedan upptäckten har utvecklingen gått snabbt och vi finner idag organisk elektronik inom många områden, till exempel OLED; alltså organiska lysdioder, som blivit väldigt populärt. I detta arbete har vi jobbat med den ledande polymer PEDOT-S. PEDOT-S leder elektrisk ström, går att lösa upp i vatten och är dessutom ganska liten, i jämförelse med de material som den ska interagera med, vilket underlättar samspelet med till exempel biologiska material.

De byggnadställningar som vi använt kommer från självorganiserade biologiska strukturer. Lite grovhugget kan man dela in biologiska material i fyra huvudgrupper; proteiner; nukleinsyror, fetter samt kolhydrater. Den första gruppen, proteiner, känner vi igen som ett viktigt födoämne men ingår också i stora strukturer som silke eller små trådar som kallas amyloid-fibrer. Bland nukleinsyrorna är DNA den kanske mest kända molekylen. Våra arvsanlag är ju lagrade i DNA-molekyler men man kan också sträcka ut eller förmå DNA att anta andra former. Fetter, eller lipider som de också kallas, kan klumpa ihop sig till små sfärer, liposomer, som ofta samverkar med våra cellmembran. Den sista gruppen är kolhydrater, som består av långa kedjor av sockermolekyler. Den kanske mest kända kolhydraten, och den absolut mest vanligaste, är cellulosa som är en viktig beståndsdel i alla växter och träd och kan användas för att göra papper. 
I denna avhandling har vi visat att det är möjligt att styra de förhållanden under självorganisationen och på så vis möjliggjort att PEDOT-S kan användas för att klä in proteintrådar, DNA, liposomer samt cellulosa. 


\section{Papers}

Papers included in the thesis

(My contribution in brackets)

Paper I Functionalisation of recombinant spider silk with conjugated polyelectrolytes

Müller C., Jansson R., Elfwing A., Askarieh G., Karlsson R., Hamedi

M., Rising A., Johansson J., Inganäs O. and Hedhammar M.

J. Mater. Chem., 21, 2909-2915 (2011)

(Part of planning, part of experimental, and part of discussion)

Paper II Electronic polymers and DNA self-assembled in nanowire transistors

Hamedi M., Elfwing, A., Gabrielsson R. and Inganäs $\mathrm{O}$.

Small 9, 363-8 (2013).

(Part of planning, part of experimental, and part of discussion)

Paper III Electronic polymers in lipid membranes

Johansson P. K., Jullesson D., Elfwing A., Liin S. I., Musumeci C., Zeglio E., Elinder F., Solin N. and Inganäs O.

Sci. Rep. 5, 11242 (2015).

(Part of planning and discussion)

Paper IV Protein nanowires with conductive properties

Elfwing A., Bäcklund F. G., Musumeci C., Inganäs O. and Solin N.

J. Mater. Chem. C, 3, 6499-6504 (2015).

(Planning, experimental, discussion, and majority of writing)

Paper V Conducting microhelices from self-assembly of protein fibrils

Bäcklund F. G., Elfwing A., Musumeci C., Ajjan F. N., Babenko V., Dzwolak W., Inganäs O. and Solin N.

Soft Matter, 13, 4412-4417 (2017)

(Planning, experimental, discussion, and major part of writing)

Paper VI DNA based Hybrid Material for Interface Engineering in Polymer Solar Cells

Elfwing A., Wanzhu C., Ouyang L. Liu X., Gabrielsson R. and Inganäs O.

(manuscript)

(Planning, material preparation, discussion, and part of writing)

Paper VII Conducting helical structures from celery decorated with metallic conjugated polymer give $\mathrm{THz}$ resonances

Elfwing A., Ponseca C., Ouyang L., Urbanovic A., Krotkus A. and Inganäs $\mathrm{O}$.

(manuscript)

(Planning, experimental, discussion, and major part of writing) 


\section{Related works not included in this thesis}

Light trapping with dielectric scatterers in single- and tandemjunction organic solar cells

Tang Z., Elfwing A., Bergqvist J., Tress W. and Inganäs O.

Adv. Energy Mater. 3, 1606-1613 (2013).

(Developed PDMS-TiO2 based light scattering material)

Charge Storage Capacity of Renewable Biopolymer/Conjugated Polymer Interpenetrating Networks Enhanced by Electroactive Dopants

Nagaraju D. H., Rebis T., Gabrielsson R., Elfwing A., Milczarek G.and Inganäs $\mathrm{O}$.

Adv. Energy Mater. 4, 1300443 (2014).

(AFM imaging, and discussions)

A renewable biopolymer cathode with multivalent metal ions for enhanced charge storage

Admassie S., Elfwing A., Jager E. W. H., Bao Q. and Inganäs O.

J. Mater. Chem. A 6, 1974-1979 (2014).

(SEM imaging, and discussions)

Fully-solution-processed organic solar cells with a highly efficient paper-based light trapping element

Tang Z., Elfwing A., Melianas O., Bergqvist J,. Bao Q. and Inganäs O. J. Mater. Chem. A 3, 24289-24296 (2015).

(Developed paper based light trapping element, SEM imaging, and discussions)

Extracting metal ions from water with redox active biopolymer electrodes

Admassie S., Elfwing A., Skallberg A. and Inganäs O.

Environ. Sci. Water Res. Technol. 1, 326-331 (2015).

(SEM imaging, EDX analysis, and discussions)

High performance PEDOT/lignin biopolymer composites for electrochemical supercapacitors

Ajjan F. N., Casado N., Rębiś T., Elfwing A., Solin N., Mecerreyes D. and Inganäs $\mathrm{O}$.

J. Mater. Chem. A 4, 1838-1847 (2016).

(SEM imaging, and discussions)

Electrochemical Synthesis and Characterization of

Interpenetrating Networks of Conducting Polymers for Enhanced

Charge Storage.

Admassie S., Elfwing A. and Inganäs O.

Adv. Mater. Interfaces 3, 1500533 (2016).

(SEM imaging, and discussions) 
Biopolymer hybrid electrodes for scalable electricity storage

Admassie S., Ajjan F. N., Elfwing A. and Inganäs O.

Mater. Horiz. 3, 174-185 (2016).

(Discussions)

Diatom frustules protect DNA from UV light

Aguirre L., Ouyang L., Elfwing A., Hedblom M., Wulff A. and Inganäs O.

(Submitted)

(SEM imaging, photoresist experiments)

Highly stable and efficient lignin-PEDOT/PSS composites for removal of toxic metals

Checkol F., Elfwing A., Greczynski G., Meheretie S., Admassie S. and Olle Inganäs

(submitted)

(SEM imaging, XPS data interpretation, discussions)

Conducting plastic with high electrosorption capacity for removal of toxic metals

Tesfaw B., Elfwing A., Greczynski G., Meheretie S., Admassie S. and Olle Inganäs

(manuscript)

(SEM imaging, XPS data interpretation, discussions)

Roll-to-Roll Printed PEDOT/PSS Plastic Film for Reduction of Toxic Chromium (VI)

Checkol F., Elfwing A., Greczynski G., Meheretie S., Admassie S. and Olle Inganäs

(manuscript)

(SEM imaging, XPS data interpretation, discussions)

Solar cell device and method for manufacture

Elfwing A. and Bergqvist J.

Patent nr SE538263.

Methods and arrangements for a solar cell device

Inganäs O., Elfwing A. and Tang Z.

Patent nr SE1450809. 


\section{Contents}

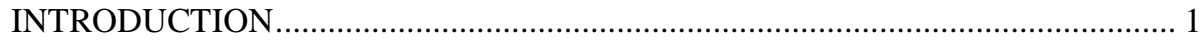

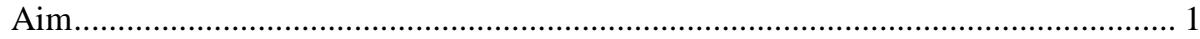

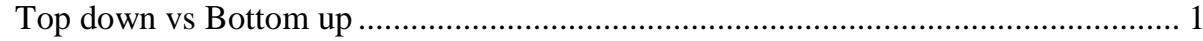

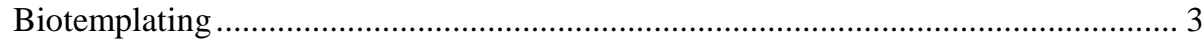

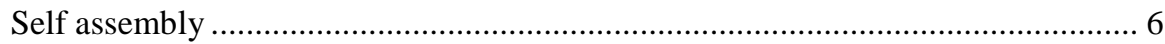

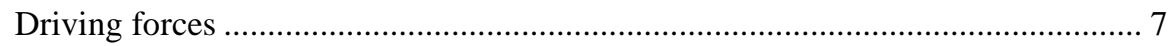

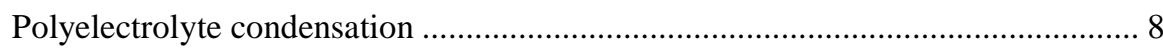

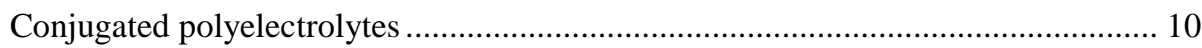

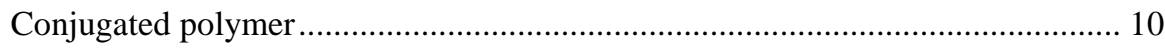

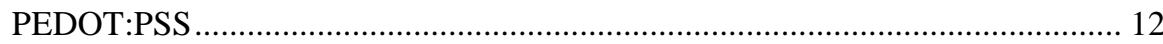

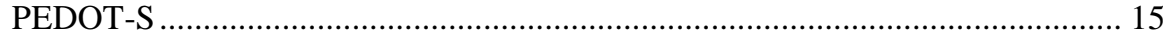

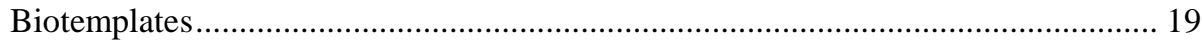

Protein and peptides ..................................................................................... 19

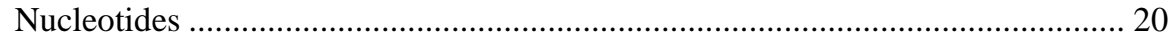

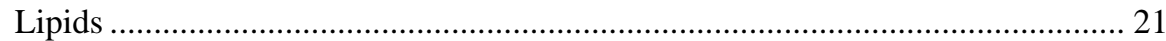

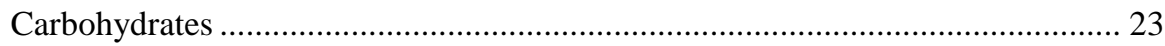

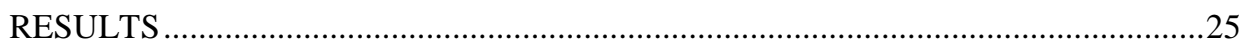

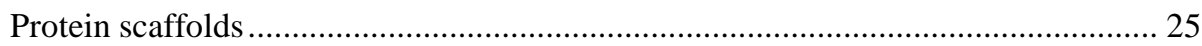

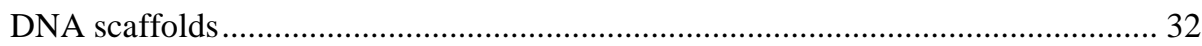

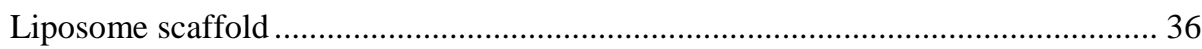

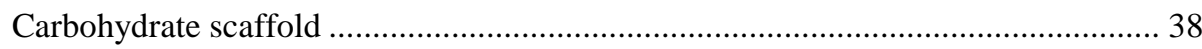

CONCLUSIONS AND FUTURE OUTLOOK .......................................................4

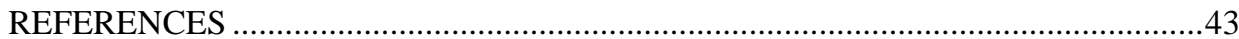

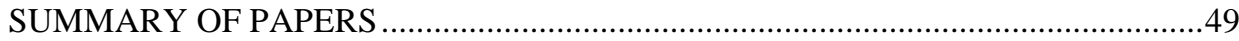

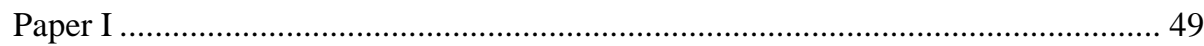

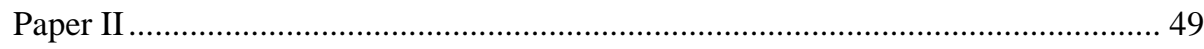

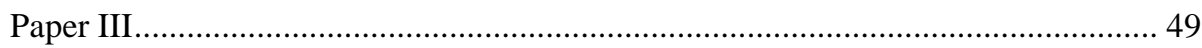

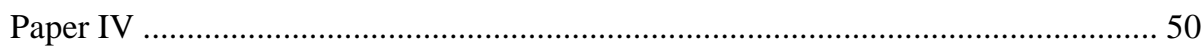

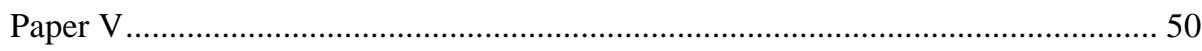

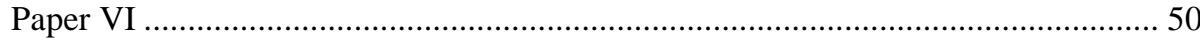




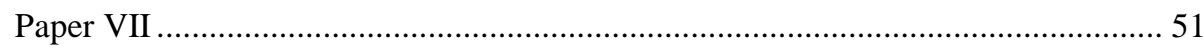

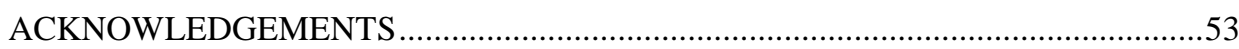


a.u.

AFM

CD

C-AFM

CTMA

DNA

e.g.

i.e.

ICD

IR

LD

Mesoscopic

PEDOT-S

PSS

PEDOT

SEM

$\mathrm{THz}$

UV

VIS

\section{Abbreviations and explanations}

Arbitary Unit

Atomic Force Microscopy

Circular Dichroism

Conductive Atom Force Microscopy

Cetyltrimethylammonium chloride

DeoxyNucleotide Acid

examplio gratia - for example

in ergo - that is

Induced Circular Dichroism

InfraRed light (800-2000 nm)

Linear Dichroism

The intermediate length scale from $\mathrm{nm}$ to $\mu \mathrm{m}$

poly(4-(2,3-dihydrothieno-(3,4-b)-(1,4)dioxin-2-yl-methoxy)-1butanesulfonate

Poly(Styrene Sulfonate)

Poly(3,4-EthyleneDiOxyThiophene)

Scanning Electron Microscopy

Tera $\left(10^{12}\right)$ Hertz -corresponding to wavelengths around $0.1 \mathrm{~mm}$

Ultraviolet light (wavelength of 200-400nm)

Visible light (400-800 nm) 


\section{INTRODUCTION}

Aim

In this thesis I will show how self-assembly processes can be used to decorate biomolecular scaffolds with a conducting polyelectrolyte. Using this biotemplating technique materials with novel optical and electronical properties have been created.

In the introduction part of this thesis I will describe the materials I have used, explain the physics of the biotemplating processes and motivate why biotemplating is so interesting.

\section{Top down vs Bottom up}

One reason why biotemplating is so interesting lies in the conceptual difference in manufacturing techniques between man and nature; the top-down vs bottom up. Top down techniques span the majority of man-made fabrication techniques. In short, larger pieces material are reduced in size or assembled together. A top down process, as depicted in Figure 1a, starts with a general starting material and as the material is gradually worked a large amount of energy is put into the process and there is a significant waste. An example is the process from a freshly cut tree to a wooden table. The log is trimmed into boards, planed, sawn into pieces and eventually glued and screwed together forming a wooden table.
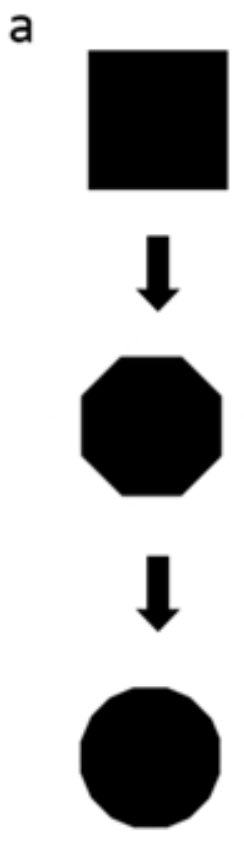

b
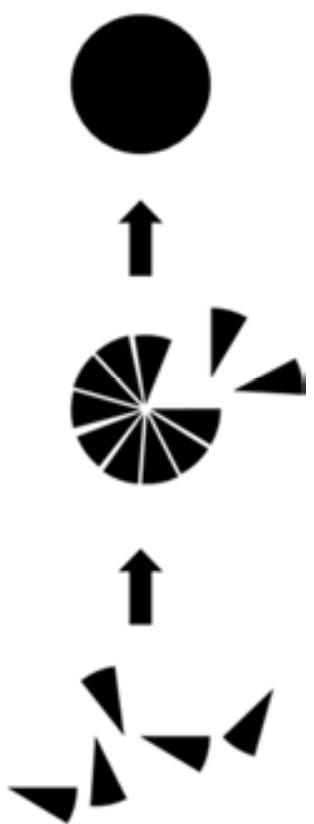

Figure 1. Schematic description of a) top down and b) bottom up processing. a) In top down processing larger starting material are serially reduced in size until the final shape is formed. b) In bottom up processing smaller building blocks are assembled together to a predestined shape. 
A bottom up process (as depicted in Figure 1b) works the other way around by assembling small parts into something bigger and where the blueprint of the finishing product is embedded in the starting material. This is how nature works; the mighty tree, later to be cut down, is created through a bottom up process where the photosynthesized carbon is chemically converted to cellulose fibrils which, through a self-assembly process, are bundled together into the wooden fibers that make up the tree. Some man controlled processes, such as bread making, are based on bottom up techniques where the sugars of the flour and the enzymes from the yeast make the dough rise.

Additive manufacturing, more commonly known as 3D printing has recently gained popularity as an alternative to traditional processing techniques. Additive manufacturing could be seen as a middle road between top down and bottom up techniques, especially since the introduction of smart materials which can change properties over time giving rise to the catch-phrase "4D-printing".

Traditional top down techniques have served mankind well, and has been optimized thought 10,000 years of advances in human technology, enabling mass production of virtually anything from cars to integrated circuitry with features below $10 \mathrm{~nm}$. But creating materials through bottom up processes is getting increasingly interesting, especially in nanotechnology. The constant decrease in transistor size as stipulated by the well-known Moore's law ${ }^{1}$ have actually started to stall. One obvious reason is the sheer size; $10 \mathrm{~nm}$ equals roughly 20 silicon atoms meaning tunneling is starting to become problematic. Another not so obvious explanation is the less known Moore's second law that, stipulates the cost of the semiconductor factories is set to double every 4 years making next generation plants extremely expensive ${ }^{2}$. Self-assembly is, as of 2017 , far from being a realistic alternative in semiconductor industry but the development potential of using a technology which is more environmental friendly, less energy demanding and more accurate is tempting.

\footnotetext{
${ }^{1}$ Moore's law was coined by Gordon Moore of Intel in 1965 and predicted the transistor density to double every year ${ }^{79}$. It should be noted that Moore's law is not a natural law. It should be seen as target to which the semiconductor industry is aiming.

${ }^{2}$ The cost of a state of the art semiconductor plant was estimated to be 100 billion SEK in 2015 .
} 


\section{Biotemplating}

Biotemplating is the art of using bottom up techniques onto structures of biological origin $^{3}$. It offers a path for using the plethora of structures already found in nature, or which can be easily synthesized. Due to their large abundance the cost of these templates are low and they furthermore show a huge variety in shape. Current semiconductor technology is manufactured on planar substrates and although there are attempts to stack structures on top of each other there are limited possibilities of creating true three dimensional objects. Nature, on the other hand, is full of 3D structures which intrinsic nanometer precision could be used to further increase the performance of bottom up devices.

A popular biotemplate technique is the modification of the scaffold to create a "handle" for the functionalization agent. This methodology, although not a general one, can be very precise placing the functional agents in certain positions within $\mathrm{nm}$ precision, an order of magnitude better than state of the art lithography techniques. Tim Liedl's group have investigated this approach extensively and used thiol chemistry to place gold nanoparticles onto pre-programmed positions on DNA origami structures. ${ }^{2-4}$ In this fashion they could decorate the DNA structure with nanoparticles in a helical fashion, generating novel materials with interesting optical activity (Figure 2).

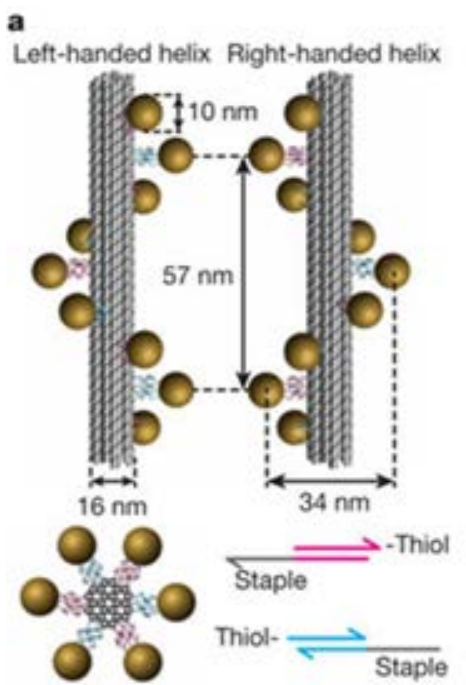

b

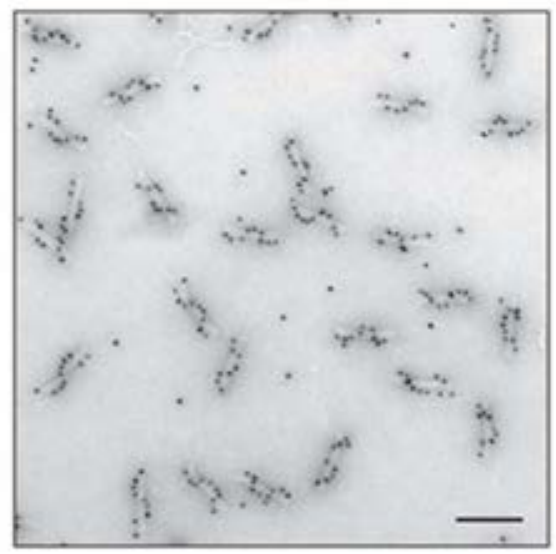

Figure 2 Gold Nanoparticle attached to DNA origami rods created structures with chiral properties. a) Schematic drawing. B) TEM image. Reprinted by permission from Macmillan Publishers Ltd: Nature. Kuzyk, A. et al. DNA-based self-assembly of chiral plasmonic nanostructures with tailored optical response. Nature 483, 311-4 (2012), copyright (2012).

\footnotetext{
${ }^{3}$ It should be noted that these structures do not necessary have to be of natural origin as we through gene technology and chemical synthesis actually can create or modify biological structures.
} 
Björn Högberg and coworkers used a similar method to create "molecular calipers"5 by adding a protein complex to a DNA origami structure which could be used to elucidate intricate receptor-ligands interactions (Figure 3).

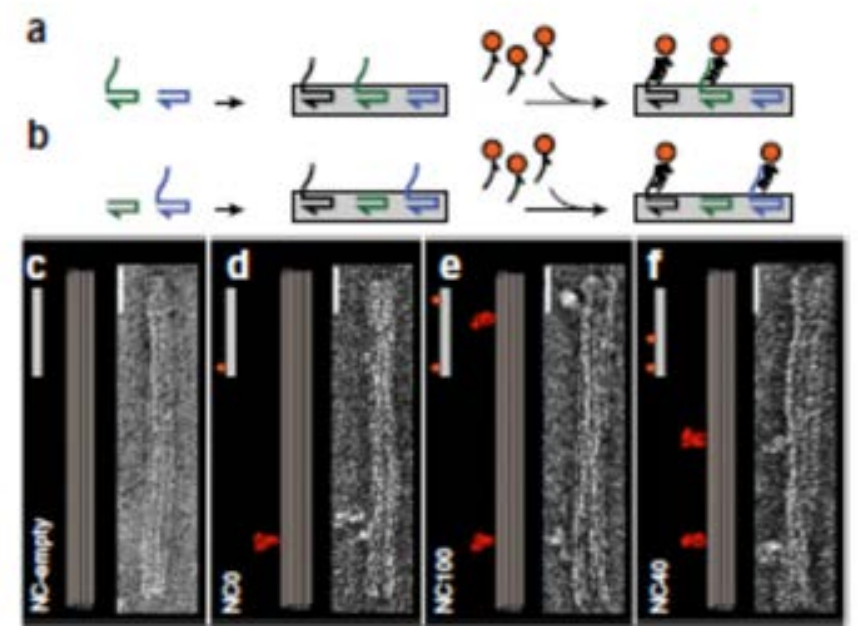

Figure 3 Protein ligands were placed on different positions on a DNA origami rod. Using these molecular caliper it was possible to study the interaction with cell surface receptor in an entire novel fashion. a) and b) show drawings of the process of attaching protein complex at predetermined positions. c)-f) show TEM images of protein complexes at various positions. Reprinted by permission from Macmillan Publishers Ltd: Nature Methods. Shaw, A. et al. Spatial control of membrane receptor function using ligand nanocalipers. Nat. Methods 11, 841-6 (2014), copyright (2014).

The advantage of using this approach is the extreme control of the process where the positioning is beyond any other technique available. The disadvantage lies in its complexity and thus cost. Today this approach is often limited to DNA origami which currently is the most developed biotemplate technology

The interest in self-assembled biotemplating have risen dramatically during the last 20 years. In one of the first significant reports Braun et al utilized biotemplating to create a silver nanowire on $\mathrm{DNA}^{6}$ (Figure 4). Silver ions coordinated by the phosphates of the DNA molecule (Figure 4a) was reduced to atomic silver creating silver nanoparticles (Figure 4b) which served as growth points for further metallization (Figure 4c). Kamata et al have shown that it is possible to use a similar approach to create optically active material by metallization of biotemplates such as the algae Spirulina ${ }^{7}$ or spiral plant structures $^{8}$ with interesting resonances in the THz region. Biotemplating has also been expanded to conducting polymers, such as polypyrrole onto $\mathrm{DNA}^{9}$, polyaniline on $\mathrm{DNA}^{10}$ and polyaniline onto amyloid fibers ${ }^{11}$. In all these cases the biotemplate was mixed with the monomer and the oxidant and the polymerization was confined onto the biotemplate thus creating conductive wires. 
a

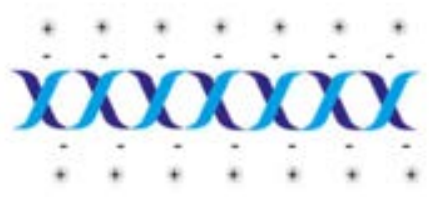

d

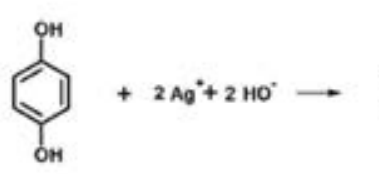

b

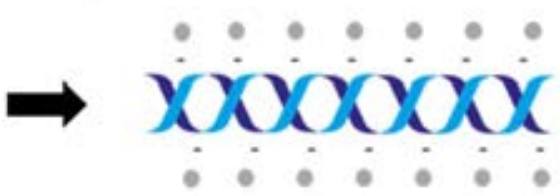

C
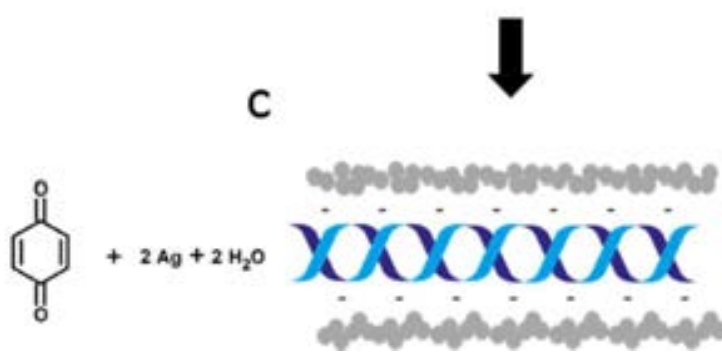

Figure 4 DNA-templated metal nanowire. a) Silver ions coordinated by the negatively charged DNA molecule. $b$ ) Upon addition of hydroquinone the silver ions are reduced. $c$ ) Further addition of silver ions and reducing agent will eventually create a confluent layer of silver nanoparticles leading to a conducting nanowire. d) The reaction where silver ions are reduced by hydroquinone. Adapted from Braun, E., Eichen, Y., Sivan, U. \& Ben-Yoseph, G. DNA-templated assembly and electrode attachment of a conducting silver wire. Nature 391, 775-8 (1998).

These early examples show how it is possible to use biotemplating as a tool to create innovative materials. However, in many cases the biotemplating procedure presented included the use of aggressive oxidants or reducing agents. Furthermore, as Watson et al points out, most reactions start at various nodes, thus rather creating a ball on a string feature, than a confluent layer ${ }^{12}$. A behavior that often ruins the intricate biotemplate shape. 


\section{Self assembly}

Atoms and molecules can interact with each other and larger entities through a number of types of interactions. Most famously and the most stable interaction is the covalent bond where, in simplified terms, two nuclei share common electrons, thus creating a covalent bond between different atoms. Supramolecular bonds is a family of non-covalent bonds such as hydrogen bond, pi-pi-interaction, electrostatic interaction, van der Waals forces etc. The supramolecular bonds are, compared to covalent bonds much more unstable but are as important. Examples of supramolecular forces can be seen everywhere in nature; from the mesoscopic DNA-double helix to macroscopic cellulose fibers. As the supramolecular binding energies is much (100 times) lower than the covalent ones, they are much more prone to break; a feature which actually is beneficial for creating ordered structures. Consider an analogy with crystal growth where any errors or high energy positions will eventually be replaced by a more perfect, low energy, position. This process is illustrated in figure 5. Figure 5a shows the attachment of a monomer to a crystal structure, but far from optimal position. If the bond energy is much higher than the available energy the crystal will end up with a mismatch. But if the available energy is higher than the bond energy, the bond will break, as depicted in Figure 5b. The monomer will eventually attach to the crystal in an optimal conformation thus enabling the growth of a perfect crystal (Figure 5c). As the available energy is crucial to facilitate the crystal like growth, the much lower bond energies of the supramolecular forces enables reaction at room temperature; a feature of uttermost importance as most biomolecules are very sensitive to changes in temperature.

a

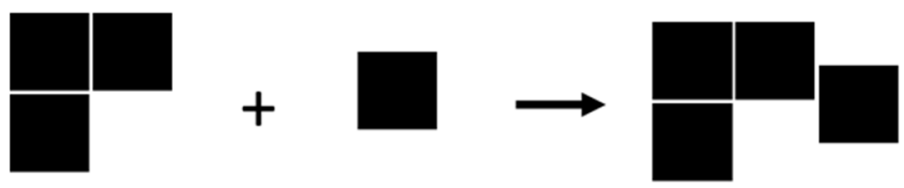

b

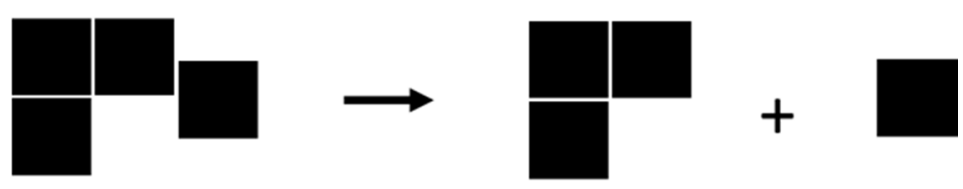

C
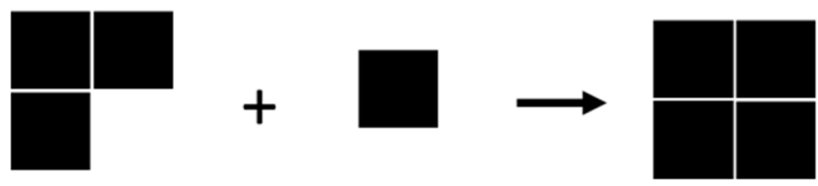

Figure 5 Schematic figure of crystal growth. a) Attachment of monomer to crystal; but at a nonoptimal position. b) De-attachment of non-optimal monomer. c) Attachment of monomer to crystal at the optimal position. 


\section{Driving forces}

In this thesis we will mainly study interaction between polyelectrolytes. Polyelectrolytes are long molecules with multiple charged side groups where DNA and proteins are two common examples. Polyelectrolytes can be either negatively or positively charged; electrostatic interaction play a major role in their configuration and ability to interact with other molecules. To understand why a set pair of polyelectrolytes will interact (or not) we have to consider the driving force of a process which can be described by Gibbs free energy;

$\Delta \mathrm{G}=\Delta \mathrm{H}-\mathrm{T} \Delta \mathrm{S}$

where $\Delta \mathrm{G}$ is Gibbs (free) energy, $\Delta \mathrm{H}$ it the difference in Enthalpy, $\mathrm{T}$ the temperature and $\Delta \mathrm{S}$ the difference in Entropy. The change in enthalpy can be understood as the net energy stored in chemical bonds before and after a reaction. If the change is negative more bonds have been broken than formed and the reaction is called exothermic meaning heat will be released. A burning log is a typical example where carbon chains are broken down and converted to carbon dioxide and water. For the opposite; if the change is negative, then there was more energy in the bonds broken than the bonds formed, the reaction is called endothermic meaning the reaction will require heating. A common reaction is the photosynthesis where carbon dioxide and water are turned into sugar molecules (carbon chains). The change in entropy is more difficult to explain but is related to thermodynamic equilibrium where the entropy is unchanged for reversible processes and will increase for irreversible processes. 


\section{Polyelectrolyte condensation}

Although we often describe a charged molecule as having a specific charge it is not entirely true as every charge is, under normal conditions, countered with a charge of opposite sign. As described in Figure 6a every charge of polyelectrolyte is coordinated by a counterion of opposite charge rendering the entire molecule "neutral". The counterions are, however, not locked by this electrostatic attraction and, since they usually are highly mobile (i.e., small), they will reversibly be interchanged with other ions in the surrounding media. However, if the charged side groups on a polyelectrolyte chain come in close contact with charges of another chain,with side groups of opposite sign, (as in Figure 6a) the two polyelectrolyte chains could complex.

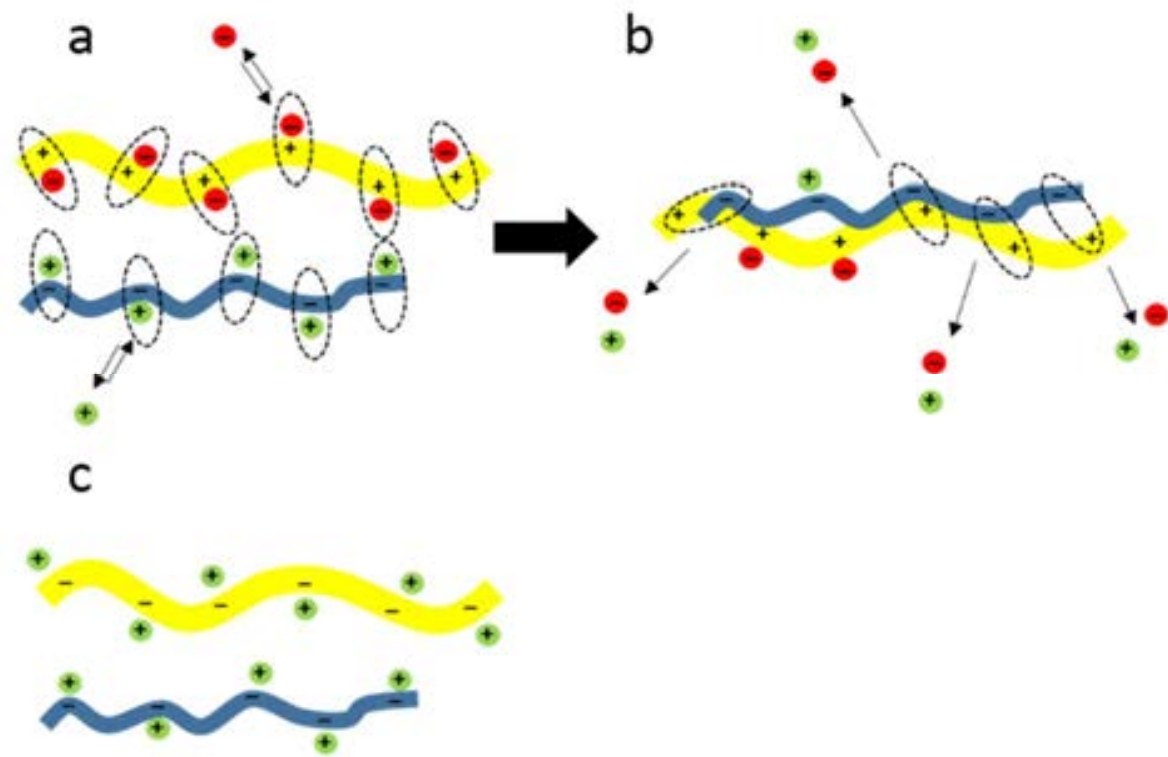

Figure 6 Self assembly of polyelectrolytes. a) A polycation (blue) and a polycation (yellow) with reversible exchange of counterions. $b$ ) Irreversible condensation of polyelectrolytes. $c$ ) Polyanions (blue, yellow) with counterions. Adapted from Bucur, C. B., Sui, Z. \& Schlenoff, J. B. Ideal mixing in polyelectrolyte complexes and multilayers: Entropy driven assembly. J. Am. Chem. Soc. 128, 13690-1 (2006).

The complexation (or condensation) of the polyelectrolytes would, however, only be possible if the coordination with the counterions can break as depicted in Figure 6b. Since the formation of a new bond between the sidegroups require bonds between sidegroups and counterions to be broken the net bond energy is very low and, as Bucur et al noted, the polyelectrolyte interaction is similar to ion exchange where the counterions are simply replaced by the charges of the polyelectrolyte. ${ }^{13}$ But since the mobility of the polyelectrolyte is much lower than the counterions this results in an irreversible process. Entropy is defined as a function of the number of microstates, meaning the number of 
possible configurations. ${ }^{4}$ In the case of the condensed polyelectrolytes (Figure $6 \mathrm{~b}$ ) the chains have moved to an interlocked state and are less able to adopt new configurations, thus limiting the number of possible microstates meaning the entropy would actually decrease. This "local" decrease of entropy is however countered by the increased number of possible configuration (microstates) for the counterions, which after the release from the polyelectrolyte, are freer to move. The release of the counterions thus play an important role as the driving force as this will increase the entropy. It has been experimentally shown that the contribution from enthalpy (bond formation/breaking) is often insignificant and that the entropic contribution, due to the release of the counterions, is much more important for polyelectrolyte condensation. ${ }^{13}$

In the case where the side groups have the same charge (as depicted in Figure 6c) the side groups of the polyelectrolytes will not be able to complex (due to absence of favorable electrostatic attraction) and since the counterions still are complexed by the side groups they will not be able to escape; thus there is no entropy gain to drive the reaction.

\footnotetext{
${ }^{4}$ The entropy ( $\mathrm{S}$ ) is defined as; $\mathrm{S}=\mathrm{k} \ln \Omega$. $\mathrm{k}$ is Boltzmann constant $=1.38064852 \times 10^{-}$ ${ }^{23} \mathrm{~m}^{2} \mathrm{~kg} \mathrm{~s}^{-2} \mathrm{~K}^{-1}$ and $\Omega$ is the number of microstates.
} 


\section{Conjugated polyelectrolytes}

\section{Conjugated polymer}

The metallic conductivity of conjugated polymers was discovered in the 1970s, a discovery well worthy of the Nobel prize in physics in 2000 awarded to Alan J. Heeger, Alan G. MacDiarmid and Hideki Shirakawa. Conjugated polymers consist of a carbon chain of alternating single and double bonds. Conjugation is, however, not sufficient for any significant electronic conductivity as the concentration of available charge carriers is far too low. To introduce more charge into a conjugated system doping is required. Doping of a system usually mean that the properties, most commonly conductivity, is altered by the addition of another species. In the world of silicon based electronics these usually mean replacing a small amount of silicon atoms with other atoms (such as phosphorous or boron). This profoundly alters transport properties through the addition of extra charge carriers in the form of hole or electron. In contrast, doping in organic electronics usually involves the addition of large amount of doping molecules, which form ion pairs or charge-transport pairs with the host polymer ${ }^{14}$.

On doping:

"In this process, the backbone of the doped polymer is oxidized or reduced, thereby introducing electronic charges onto the polymer chain. It is these mobile electronic charges that are responsible for the electrical conductivity of the doped polymer. More generally, this process (n-type or p-type doping, reduction or oxidation) is responsible for all the changes in electronic structure that occur after doping, including changes in the optical and infrared absorption." (Patil, A. O. et al. Self-doped conducting polymers. Synth. Met. 20, 151-159 (1987).

Doping causes a fundamental change in electronic structure in the molecule. As schematically shown in reaction (i) the reduction or oxidation of the polymer backbone of the conjugated polymer (CP) by a oxidizing or reducing agent (D) results in localized charges on the polymer chain. The net charge is balanced by the corresponding counterions.

$\mathrm{CP}+\mathrm{D} \rightarrow \mathrm{CP}^{+}: \mathrm{D}^{-}$or $\mathrm{CP}^{\prime}: \mathrm{D}^{+}$

In p-type conducting polymers, it is often found that doping is associated with the localized mono and divalent cations, which further gives characteristic optical absorption that can be classified as polarons and bipolarons. ${ }^{15}$ These charges lead to the rise of free charge carriers that can be transported along the polymer chain or hop onto the adjacent molecules and are thus responsible for the conductivity in the conjugated polymers.

To maintain the doping, the dopant must remain in the material; most commonly as an external ion which will act as counter-ion to the charge carriers in the conjugated backbone of a conjugated molecule. In the perhaps most used organic electronic polymer PEDOT:PSS where PEDOT (3,4-ethylenedioxythiophene) is the conjugated polymer and PSS (polystyrene sulfonate) acts as the counter ion (Figure 7). 

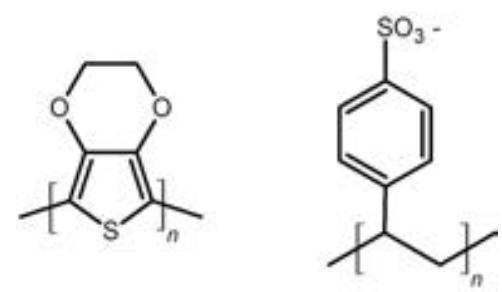

Figure 7 General structure of PEDOT:PSS. The PEDOT chain is intermixed with the poly(styrene sulfonic acid) chain and the sulfonic acid side groups are interacting with the delocalized holes in the PEDOT backbone.

Using electrochemical or chemical routes it is possible to reverse the doping process, effectively de-doping the material. As noted above the polaron and biopolaron on the conjugated backbone are stabilized by a dopant molecule. If this relation is disturbed the material properties will be dramatically altered. For an electrochemical half-cell this can be described in a generalized form for p-type material where $\mathrm{CP}$ is the conjugated polymer, $\mathrm{D}$ is the dopant, e is electron and semicolon indicating a non-covalent complex between molecules as;

$$
\mathrm{CP}^{+}: \mathrm{D}^{-}+\mathrm{e}^{-} \rightarrow \mathrm{CP}^{0}+\mathrm{D}^{-}
$$

By applying a negative bias, thus feeding the material with electrons $\left(\mathrm{e}^{-}\right)$the material will be reduced $\left(\mathrm{CP}^{+} \rightarrow \mathrm{CP}^{0}\right)$ effectively decreasing the conductivity of the material. As the positive charge of the conjugated backbone disappear the mutual electrostatic attraction is lost and the dopant will be released from the complex.

In the special case where the dopant $\mathrm{D}$ is immobile and $\mathrm{M}^{+}$is a ubiquitous cation from the electrolyte;

$\mathrm{CP}^{+}: \mathrm{D}^{-}+\mathrm{e}^{-}+\mathrm{M}^{+} \rightarrow \mathrm{CP}^{0}: \mathrm{D}^{-}: \mathrm{M}^{+}$

the cations $\left(\mathrm{M}^{+}\right)$will be incorporated into the complex, effectively causing the material to swell, a phenomena which have been utilized to create polymer actuators ${ }^{16}$. Since the reaction is reversible it can also be used to release ions embedded in the conjugated matrix ${ }^{17}$ or be used as water-splitting free electrodes in microsystems ${ }^{18}$. As the conjugated polymer in both cases is reduced the electronic properties are dramatically changed, which have been used in non-linear electronics such as electrochemical transistors ${ }^{19}$. Furthermore, due to change in the electron configuration the light absorption of the conjugated polymer will change paving the way for electronic displays ${ }^{20}$.

De-doping can also be achieved by chemical routes; by adding strong reducing agents such as hydrazine ${ }^{21}$ or other electron donor molecules such as tertiary amines ${ }^{22}$. The conjugated polymer $(\mathrm{CP})$ will be reduced by the reducing agent $(\mathrm{R})$ whereby the dopant (D) can complex the reducing agent and be released from the polymer matrix;

$\mathrm{CP}^{+}: \mathrm{D}^{-}+\mathrm{R} \rightarrow \mathrm{CP}^{0}+\mathrm{D}^{-}: \mathrm{R}^{+}$ 


\section{PEDOT:PSS}

Commercial variants of PEDOT:PSS are dilute water based suspension where the PSS content is usually 2-3 times higher than the PEDOT content. Even though PSS is an insulator the very high level of doping creates a material with a conductivity of over 1000 $\mathrm{S} / \mathrm{cm}$. Although PSS is an insulator it is very important for the functionality of PEDOT:PSS. PEDOT is a very short molecule whereas PSS is a much longer polymer and it is thought that the shorter PEDOT molecules are arranged onto the longer PSS chain (as depicted in Figure 8b). This notion was supported in an experiment using linear dichroism (LD) spectroscopy where dilute solutions of commercial PEDOT:PSS (PH1000 and 4083, Hereus; Germany) was subjected to shear forces in a rotary cuvette system. In LD the UV-VIS absorption of polarized light along and perpendicular to the shear direction can be used to determine how the light absorbing species are aligned. Negative sign usually indicates perpendicular alignment and positive sign alignment along the flow. This technique has been used in the study of other elongated (and stretchable) polymers such as DNA ${ }^{23}$ and amyloid fibers ${ }^{24}$. In our experiment we showed (Figure 8c) that it was possible to stretch out (as depicted Figure 8d) the PEDOT:PSS chain of the high conductive variant PH1000 to a much higher degree than the low conductive variant 4083 . 
a
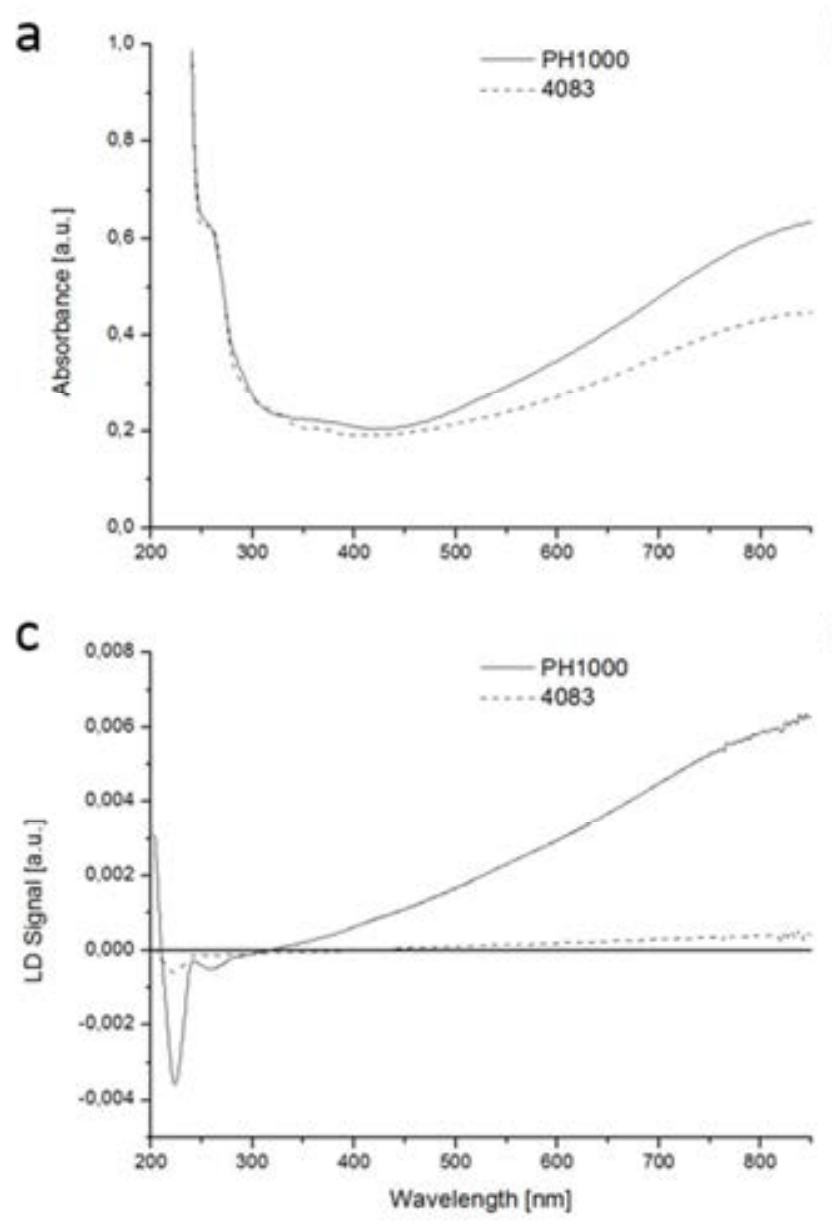

b

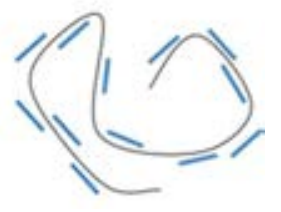

d

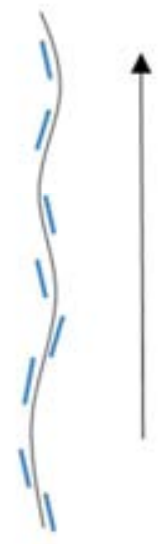

Figure 8 Conformation of PEDOT:PSS. a) UV-VIS absorption spectra of PH1000 (solid line) and 4083 (dotted line) of the in $b$ ) naively drawn assumed random coil configuration of PEDOT:PSS with PEDOT depicted in blue and PSS as grey lines. c) LD spectra PH10OO (solid line) and 4083 (dotted line) of the in d) naively drawn assumed stretched out configuration of PEDOT:PSS in a sheer flow (arrow indicating sheer direction) with PEDOT depicted in blue and PSS as grey lines. [Unpublished results]

In the deep UV-region the styrene sulfonate absorption peak is visible with a negative sign, indicating an alignment across the flow whereas the PEDOT-like absorption have a positive sign in the visible region indicating alignment along the flow direction. As PSS is a much longer molecule we argue that the PSS molecule is stretched out by the shear forces and it is likely the length of the PSS molecule, and thus the ability to stretch in a flow, is responsible for the dramatic difference between the two variants. It should be noted that the PEDOT content, viscosity and possible additives also differ between the variants meaning it is difficult to judge how big impact this difference in length of PSS 
molecule actually have on the conductivity of the material, although the UV-VIS spectrum of the samples are, as seen in Figure 8a, similar. But it is not unlikely that the increased order of a conducting material (onto a non-conducting matrix) would be beneficial for charge transport.

The additional dopant is a problem in self-assembly since steric hindrance of the dopant will interfere with the delicate and short-range interactions between the polymer and scaffold. A further problem is the phase separation of the material where PSS forms insulating domains ${ }^{25}$. There are however reports that PEDOT:PSS can be used in selfassembly systems such as Layer-By-Layer (LBL) ${ }^{26}$. As LBL is mainly restricted to planar structures self-assembly on more complex structures would require a system without a bulky dopant. Poly(4-(2,3-dihydrothieno-(3,4-b)-(1,4)dioxin-2-yl-methoxy)-1butanesulfonate) (PEDOT-S) is a self-doped, water soluble conductive polymer suitable for self-assembly. 


\section{PEDOT-S}

The synthesis of poly(4-(2,3-dihydrothieno-(3,4-b)-(1,4)dioxin-2-yl-methoxy)-1butanesulfonate) (PEDOT-S) was first reported by Stephan et al in $1998^{27}$ but the procedure to create a fully self-doped and water soluble system was later developed by Roger Gabrielsson ${ }^{28,29}$. In short the monomer salt EDOT-S:Na (Figure 9) was diluted with water and mixed with the oxidant sodium persulfate with iron(II)chloride as a catalyst. The monomer to oxidant ratio was 1:1 and after three hours of incubation, where the solution quickly turn dark blue, the reaction was stopped by adding acetone. The polymer precipitated in the acetone solution and the precipitate was washed several times and resuspended in water to remove the remaining oxidant. After wash, the polymer PEDOT$\mathrm{S}: \mathrm{Na}$ was loaded to a cation exchanger to remove the sodium ions and create PEDOT$\mathrm{S}: \mathrm{H}$. After subsequent size exclusion chromatography and dialysis against deionized water using a $3000 \mathrm{~g} / \mathrm{mol}$ cut off membrane to remove smaller oligomers and reactants, the final product was freeze dried creating dark blue flakes of polymer which easily dissolved into water. It should be noted that the dissolved polyelectrolyte is largely deprotonated and the resulting solution have a $\mathrm{pH}$ of around 2 .
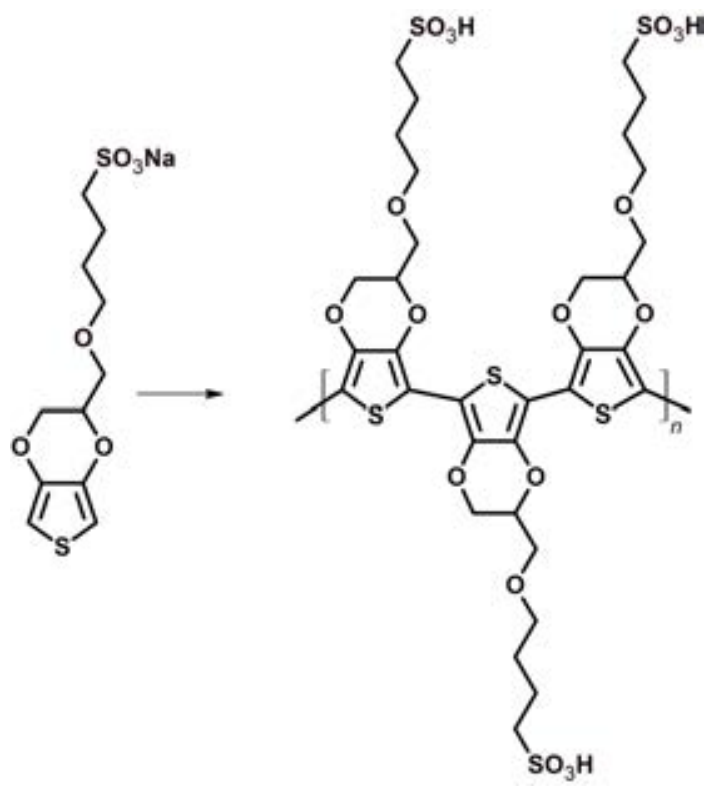

Figure 9 Schematic polymerization route of PEDOT-S. The monomer salt (EDOT-S:Na) is polymerized using oxidative polymerization using sodium persulfate as main oxidant and iron(II)chloride in catalytic amounts. After washing the polymer is subjected to cation exchange resin to replace the sodium ions with protons. Adapted with permission from ${ }^{29}$.

PEDOT-S is a polymer of the monomer EDOT-S although the prefix oligo should be more fitting since the molecule is not very long. The length of the molecule has been measured using Gel Permeation Chromatography (GPC) and the size was determined to be 16 monomers in length ${ }^{29}$. Although GPC on linear molecules can give an size overestimation by up to $30 \%^{30}$, our MALDI-TOF experiment (Figure 10) have shown 
that up to 16-meres are detectable although we were unable to determine the exact distribution. The relative small size of the PEDOT-S molecule is actually beneficial since the diffusion constant will be high and it will experience less steric hindrance in the interaction with (much larger) biomolecules.

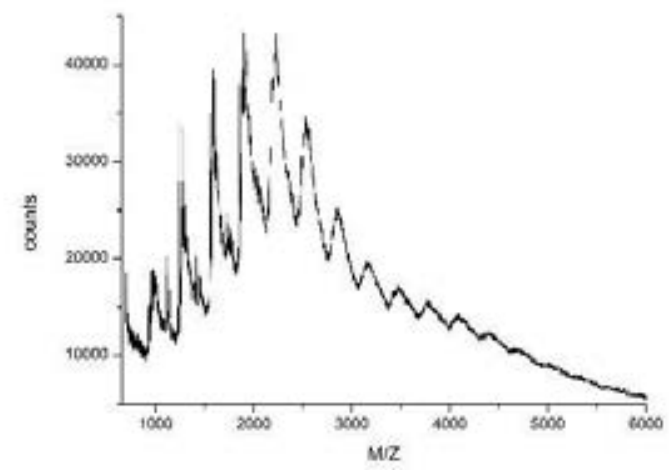

Figure 10 MALDI-TOF spectrum of dropcast PEDOT-S with dihydroxybenzene as matrix. Given a monomer weight of $255 \mathrm{~g} /$ mole oligomeric fractions from 3 to 16-mers are detectable in the spectrum. Reproduced with permission from ${ }^{31}$.

It is speculated that a PEDOT-S molecule is mainly doped by sidechains from neighboring PEDOT-S molecules which would explain the nm-sized clusters seen in Differential Light Scattering (DLS) experiments. Experiments have also shown that the doping level of PEDOT-S indicates that $30 \%$ of the sulfonic acid side chains are used for (self)-doping ${ }^{29}$. For PEDOT-S this property means the conductivity can be as high as 30 $\mathrm{S} / \mathrm{cm}$ without any addition of an external additive ${ }^{29}$. This conductivity is of course much lower than compared with commercially available PEDOT variants such as PH1000 which, with the correct additive, can reach a conductivity of $1000 \mathrm{~S} / \mathrm{cm}$. And, as we have noted before, the real difference in conductivity between PEDOT-S and PEDOT might very well be explained by the higher level of order due to the alignment of PEDOT onto the PSS chain. Interestingly enough the conductive properties of PEDOT-S are retained even after association with biomolecules although no thorough calculation of the conductivity of associated molecules have been done. The color of PEDOT-S is dark blue and reflects the level of doping due to polaron absorption. At higher $\mathrm{pH}$ the polymer is de-doped, causing the red and near infrared absorption to decrease and a signature absorption (pi-pi* transition) at $600 \mathrm{~nm}$ to increase, causing a more light blue color (See Figure 11). This color change is also true when dedoping a thin film of PEDOT-S using electrochemical means ${ }^{28}$. 


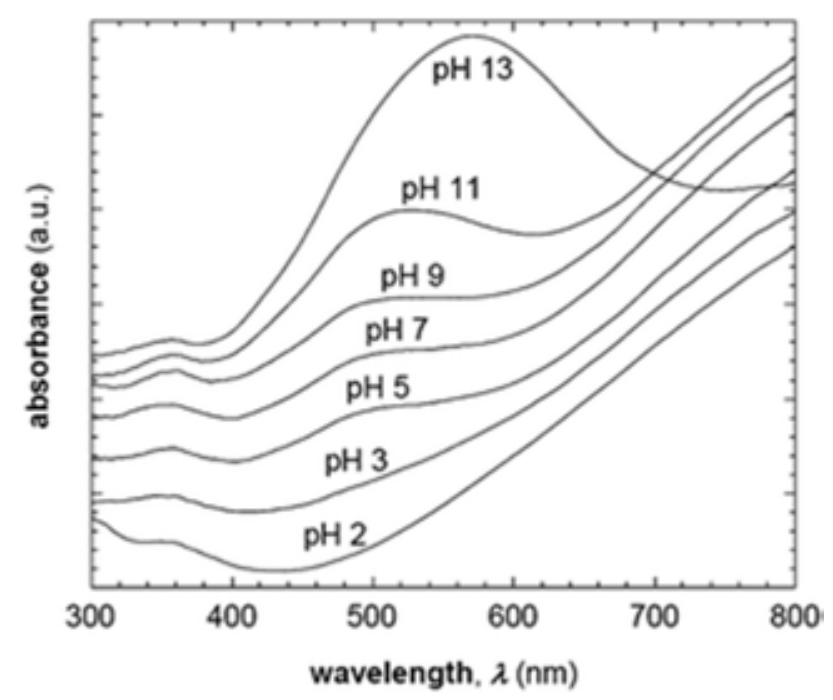

Figure 11 UV-VIS spectra of PEDOT-S when subjected to different $p H$. Reproduced with permission from ${ }^{32}$.

Solubility and preferably water solubility is crucial in self-assembly, especially for biotemplating. The above mentioned PEDOT molecule is notoriously hard to dissolve. Solubility makes interaction with other species possible and water solubility is for both practical and environmental reason the most coveted property. Since PEDOT-S, in this work, is used with biomolecules which usually are very sensitive to other solvents, this property has practical implication. Since most of the sulfonic acid sidechains are not involved in the self-doping process these highly charged parts of the molecule is crucial for water solubility and interaction with biomolecules. The water solubility of PEDOT-S exceeds $20 \mathrm{~g} / \mathrm{L}$.

The PEDOT-S molecule, with is intriguing properties, have found applications in selfassembly $^{31-37}$, solar cells ${ }^{38,39}$, light emitting diodes ${ }^{40}$, bioorganic electronics ${ }^{29,41,42}$, electrochemical transistors ${ }^{43}$ and nanoelectronics ${ }^{44}$. Cai et al used PEDOT-S as hole transporting layer in organic solar cells and used UV-ozone to increase the workfunction of the material ${ }^{39}$. Lee et al used $\mathrm{pH}$ neutral PEDOT-S:Na to replace the acidic PEDOT:PSS as an interlayer and work function modifier together with $\mathrm{ZnO}$ to create tandem solar cells with $10.2 \%$ power conversion efficiency and increased long term stability $^{38}$. Cutler et al used the negatively charged PEDOT-S and the positively charged poly(allylamine hydrochloride) (PAH) to create a layer-by-layer (LBL) hole injection layer in organic light emitting diodes ${ }^{45}$. Their LBL material consisting of a conductor (PEDOT-S) and an insulator (PAH) was found to have similar performance as PEDOT:PSS. Persson et al made use of the water solubility and the high negative charge of the molecule when creating a switchable surface ${ }^{29,41,42}$. Applying a negative bias to the PEDOT-S film causes it to swell and eventually disrupts due to a high influx of ions into the film. This switchable surface could be used as a cell release material that would allow adhered cells to be harvested without disrupting the cells. Zeglio et al used PEDOT-S together with a luminescent poly(2-(3-thienyl)ethoxy-4-butylsulfonate) (PTEB-S). A 
polyelectrolyte blend was formed in spite of both polyelectrolytes being negatively charged and the resulting material could be used to create electrochromic devices as well as organic electrochemical transistors running in depletion as well as accumulation mode $^{43}$. Hamedi et al used PEDOT-S to be able to create nanometer sized finger electrodes fabricated by soft lithography ${ }^{44}$. This technique could be used to bridge nanoand microelectronics. Due to the water solubility of the molecule it was possible to use capillary forces in nanometer sized channels to create a conductive pattern. A feat not possible by using PEDOT:PSS most probably due to the phase separation of the material where the insulating PSS is known to form insulating areas when the solvent evaporates ${ }^{25}$. 


\section{Biotemplates}

Structural biomolecules can roughly be divided into four distinct groups depending on general chemical structure; protein (or polypeptides), nucleic acids, lipids and carbohydrates.

\section{Protein and peptides}

a

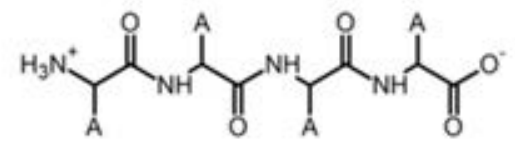

b

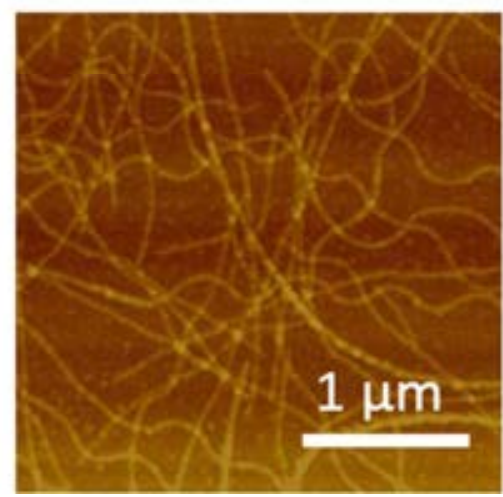

C

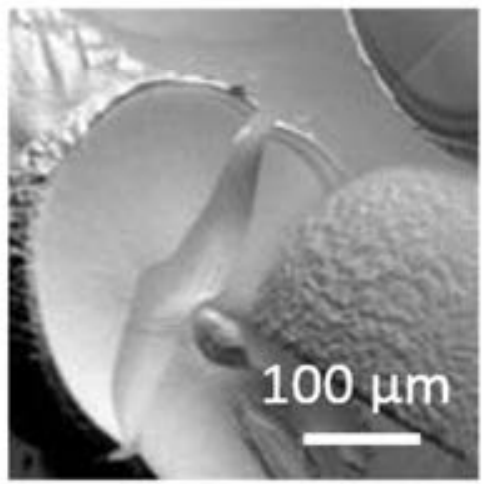

Figure 12 Protein and peptide structure. a) General peptide structure. The side groups A determine the functionality. These functionalities can be positively or negatively charged, polar or non-polar. b) AFM image of insulin amyloid fibrils. c) SEM image of amyloid spherulites.

Proteins, from the greek word protos meaning first, was the first biomacromolecule to be characterized by science. Protein is one of the most important constituents of our bodies and comes in many forms and with a wide a variety of functions, owing to extremely rich chemistry. Proteins or more correct polypeptides consist of long chains (Figure 12a) of amino acid molecules linked together by covalent peptide bonds where each amino acid can have a different functionality. Amino acids can be either polar, non-polar, positively or negatively charged. These features are very important as the polypeptide chain will eventually fold into a functional protein where the fold is held together by supramolecular forces. Large protein structures are found inside our cells where actins creates the cytoskeleton and where collagen make up our tendons and ligaments. Polypeptides also make up macroscopic fibers such as silk. Apart from naturally occurring structures there are a number of synthetic and semisynthetic variants based on peptides where one of the most characterized is bi-phenylalanine ${ }^{46-48}$ which can be used to create mesoscopic structures. The synthetic versions have the advantage of being very well characterized, lacks the batch-to batch variation of natural materials but are all profoundly simple. The 
use of natural occurring materials on the other hand is hampered by unreliable variations but, on the other hand, come in a plethora of forms. Several proteins and peptides are known to self-assemble into beta-sheet rich aggregates. These in vivo amyloids structures are a key symptom of maladies such as Creutzfeldt Jacob's disease, Alzheimer's disease and systemic amyloidosis. Some of the raw material such as insulin, hen egg white lysozyme etc are easily obtained (i.e., cheap) and can form amyloid like fibrils under certain conditions in vitro. It is since long known that if insulin, for example, is dissolved at low $\mathrm{pH}$ and gently heated, the protein molecules will, overnight, unfold and create fibrils ${ }^{49}$ rich in beta-sheet. (Figure 12b show an AFM image of insulin amyloid fibrils and Figure 12c an SEM image of a larger spherulite structure based on insulin amyloid fibrils. Polypeptide based material are generally very stable and material with a high beta-sheet content such as silk fiber and amyloid fibrils are especially durable.

\section{Nucleotides}
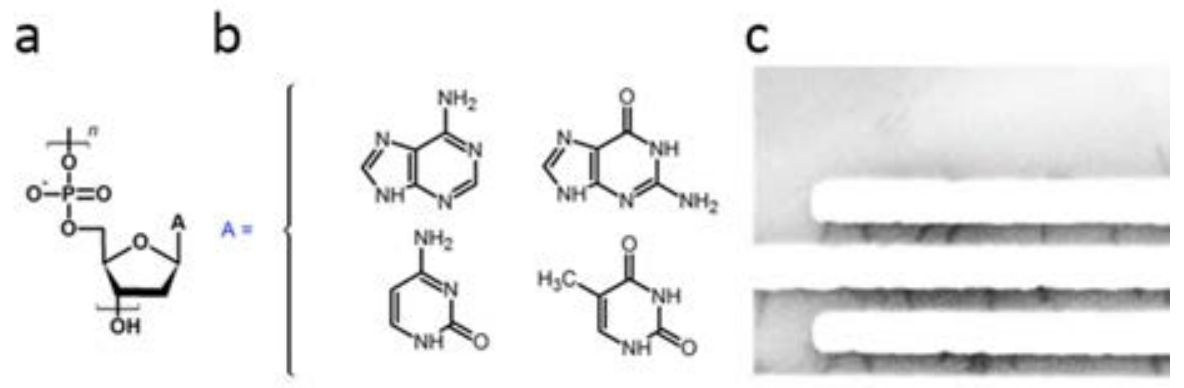

Figure 13 DNA a) The general structure of DNA consisting of a sugar-phosphate backbone with a side group of b) either adenine, thymine, cytosine or guanine. c) DNA origami nanorods (dark structures) bridging the gaps of finger electrodes (horizontal white structures).

The polynucleotides was the last major class of biomacromolecules to be fully identified, with the DNA structures most famously described by Watson and Crick in the $1950 \mathrm{~s}^{50}$. The polynucleotides, be it DNA, RNA or derivative thereof consist of a sugar-phosphate backbone (Figure 13a) with nucleobase sidechains (Figure 13b). The backbone give mechanical stability and the nucleobase sidechains hydrogen bonds to a complementary nucleobase on another strand. As the backbone is highly negatively charged the molecule can easily be stretched out. DNA is not known to exist in any structural function in nature but due to the ease of synthesis and the simplicity in base-pairing have created the novel field of DNA-nanotechnology. Already predicted in the 1980 s by Seeman ${ }^{51}$, the term DNA origami was coined by Rothemund in $2006^{52}$ to describe the art of "programming" a structure. To date planar and three dimensional structures (Figure 13c) can be generated and DNA origami is by far the most developed nanotechnology based on biological material. DNA based material, however, are very sensitive and will quickly degrade at non-physiological $\mathrm{pH}$. 
Lipids

a

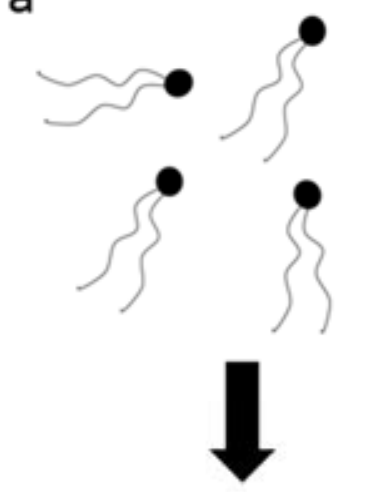

C

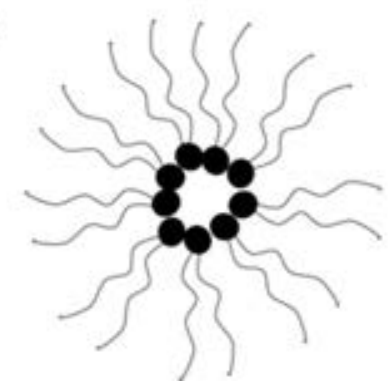

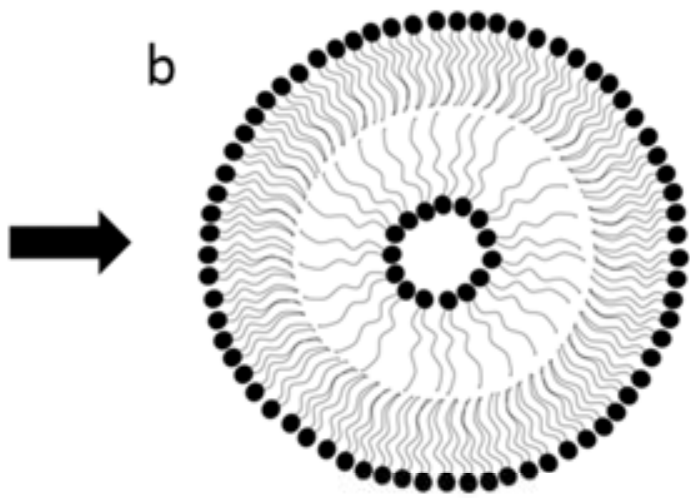

d

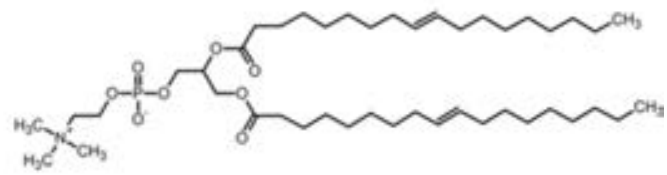

Figure 14 Lipids. a) Sketch of phospholipid with a polar head (black circle) and non-polar hydrocarbon tails (black lines). b) In aqueous media the lipids will self-assembly into spherical structures where the hydrophilic heads are exposed to the surrounding media while the exposure of the hydrophobic tails are minimized. c) In non-polar solvent the lipids are self-assembled into the inverse of $b$ ) where the non-polar tails are exposed and the polar heads are hidden inside the structure. d) Structure of DOPC.

Lipids differs from the other classes since lipids are not generally thought of as polymers (Figure 14d show the chemical structure of DOPC) and lack a covalent bonded backbone. Nevertheless it is one of the most important classes of biomolecules and constitute the majority of the lipid membranes encapsulating most (if not all) living cells. The most studied lipid systems are the phospholipids with a charged phosphor "head" with a long carbon tail, often 16-18 carbon chain (A naïve sketch is found in Figure 14a). This is an amphiphilic structure; amphiphilic meaning it has both a hydrophilic (water loving) and a hydrophobic (water loathing) part. This amphiphilic structure will self-assemble, depending on the polarity of the media, due to the hydrophobic effect as depicted in Figure 14b and Figure 14c. The hydrophobic effect (sometimes attributed to as hydrophobic interaction) is an entropic driven process with contributions from the enthalpy close to zero. The hydrophobic effect is a major contributing factor in the selfassembly of amphiphilic molecules where water molecules are released when the hydrophobic moieties are packed together. Even though the hydrophobic parts are more ordered the total entropy is actually increased, since the water molecules can move around 
more freely. Artificial lipid materials have found use in e.g., drug delivery ${ }^{53}$ and nanotechnology ${ }^{54}$. 


\section{Carbohydrates}

a

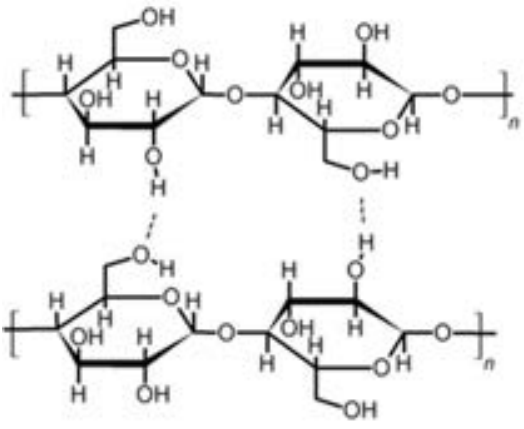

b

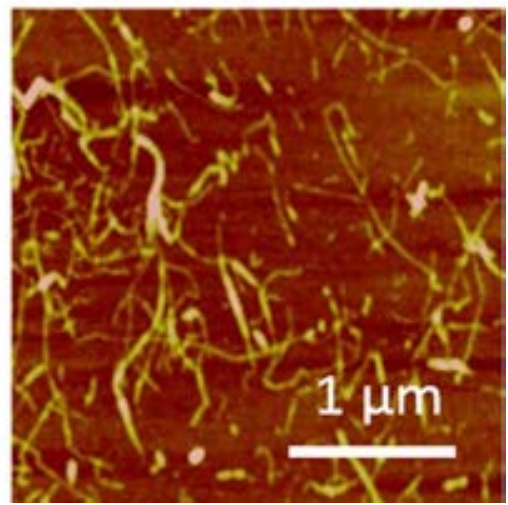

Figure 15 a) Molecular structure of cellulose. b) AFM image of nanocellulose.

Carbohydrates consist of a large family of molecules based on various sugar molecules. Apart from small molecules such as mono and di-saccharides the carbohydrate polymers includes cellulose, hemi-cellulose etc. Carbohydrates play an important role in all life and make up the cell walls of plants, making cellulose the by far most abundant biopolymer on the planet. Cellulose chains are self-assembled into larger structures mainly held together by hydrogen bonding (see Figure 15a) although hydrophobic effect may play a role $^{55}$. Cellulose fibers have found use in the paper and pulp processes creating paper, cartons etc. Nanocellulose (see Figure 15b) is the semisynthetic (engineered) version of cellulose where the cellulose fibers have been degraded into smaller nanofibrils. These processed building blocks have amongst others found use in batteries ${ }^{56}$. Cellulose based material can be extremely resilient compared to the previously described classes of biomaterials, although lacking much of the chemical richness which signifies e.g., proteins. 


\section{RESULTS}

\section{Protein scaffolds}

Based on the promising interaction studies of luminescent conjugated polymers and insulin amyloid fibrils ${ }^{57,58}$ PEDOT-S was introduced to decorate insulin like amyloid fibrils ${ }^{34}$. Hamedi et al used the conjugated polymer to decorate the fibrils creating conductive networks of fibrils which were characterized by TEM and AFM. These networks could also be turned into depletion mode electrochemical transistors. The concept of ordering PEDOT-S onto biotemplate was later expanded into peptide based material $^{33}$ where Hamedi et al showed that PEDOT-S could selectively decorate one peptide in a two-peptide system. This feature could be used to influence the self-assembly of gold nanoparticles coated with peptides and to create conductive networks of gold nanoparticles with PEDOT-S coated peptides.

Niclas Solin and coworkers have in a number of paper developed a novel method of dispersing functional material inside insulin amyloid fibrils where the functional material; the guest; is internalized into to amyloid fibril (the host) ${ }^{24,59,60}$. This method, by "grinding" the native insulin with the guest material and subsequent fibrillation, have been shown to be possible for a number of guest such as fluorescent molecules ${ }^{24}$, phosphorescent compounds $^{59}$ and magnetic nanoparticles ${ }^{61}$ which could be used in OLEDS ${ }^{60}$ and to influence the fibrillation process ${ }^{62}$. In PAPER IV we utilized this concept as a novel method of examining the decoration of an amyloid structure. The internalized dye, in this case 4,4'-bis(2-methoxystyryl)-biphenyl (BMSBP) is emitting at $440 \mathrm{~nm}$ when excited at $405 \mathrm{~nm}$ as depicted in Figure 16a. After addition of PEDOT-S, however, the emission is quenched, as evident in the spectra presented in Figure 16c. This phenomena can be explained by Förster Resonance Energy Transfer (FRET) where the excited dye is relaxed through non-radiative pathways. FRET between two molecules is generally only possible where the distance between the dye and the polymer is very small $(<10 \mathrm{~nm})$ and where the emission of the dye is coinciding with excitation of acceptor. The size of an insulin amyloid fibril is in the range of 5-10nm meaning the distance between a decorated polymer and an internalized dye is short enough to enable efficient energy transfer. As PEDOT-S is a metallic polymer, meaning it has no excitation peak, but rather a broad absorption it is possible to absorb any available energy. A plausible model for the decoration is depicted in Figure 16b supported by the peak emission curve indicating a saturation process as seen in Figure 16d. 

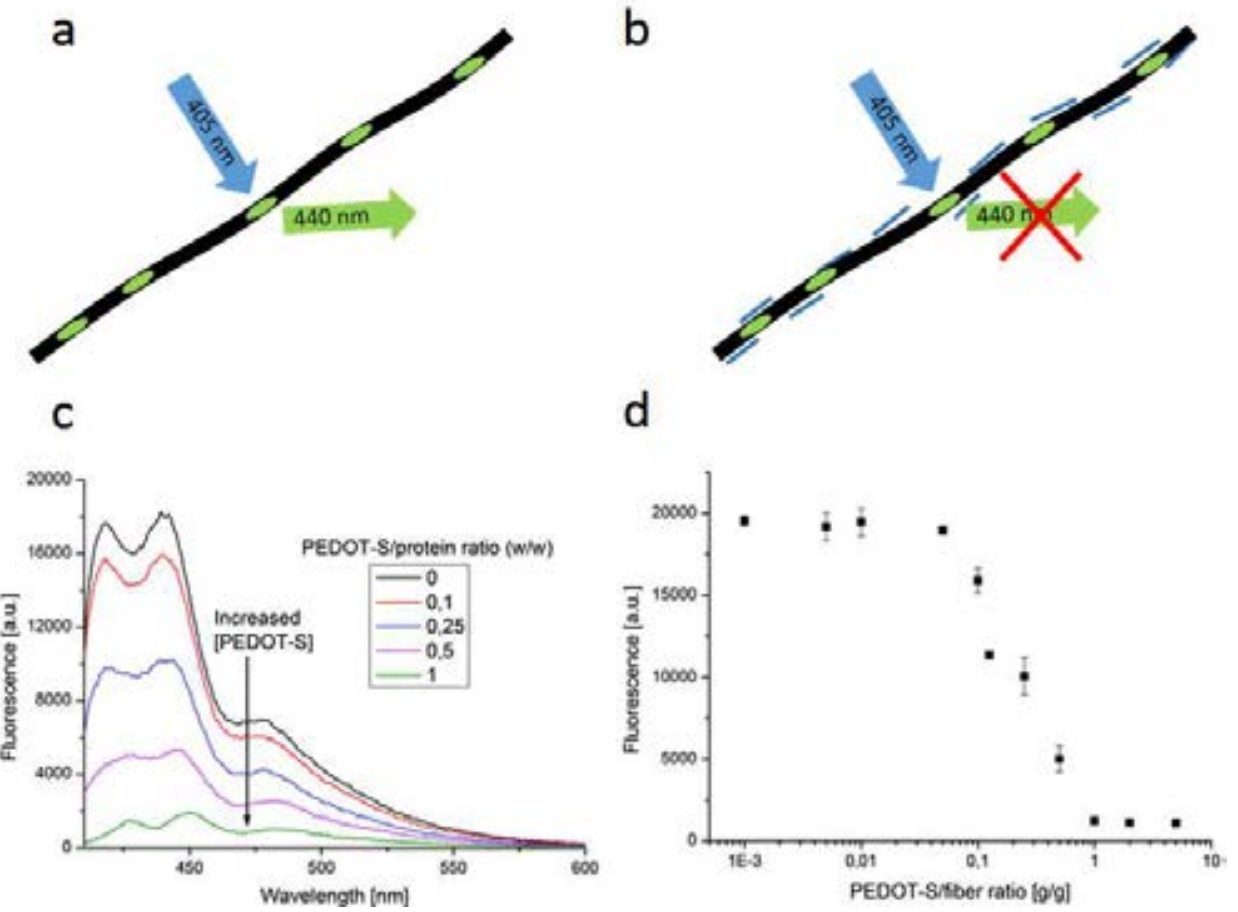

Figure 16 Fluorescence quenching of an internalized dye. a) Naïve illustration of an amyloid fibril with an internalized dye. b) Nä̈ve illustration the decoration of PEDOT-S ont an amyloid fibril with an internalized dye c) Emission spectra of an internalized dye in amyloid fibrils decreases upon addition of PEDOT-S. d) Peak emission as a function of added PEDOT-S. Adapted with permission from ${ }^{31}$.

This was the first example of energy transfer from an internalized dye and a decorating molecule on an amyloid fibril.

Regarding the alignment of PEDOT-S onto the much larger protein structure as depicted in Figure 16b Herland et al were using single molecule spectroscopy to be able to determine that the conjugated polymer PTAA is aligned along the axis of amyloid fibrils $^{63}$. As the alignment of PTAA along the axis of amyloid fibrils was confirmed by Wigenius et $a l^{64}$ using linear dichroism (LD) spectroscopy we made a similar experiment where PEDOT-S was allowed to interact with hen egg white lysozyme (HEWL) amyloid like fibrils. The resulting LD spectrum (see Figure 17) revealed a PEDOT-S like signal where the positive sign indicate an alignment along the fibril axis. This result is in line with the similar experiment with PEDOT:PSS as seen in Figure 8. 


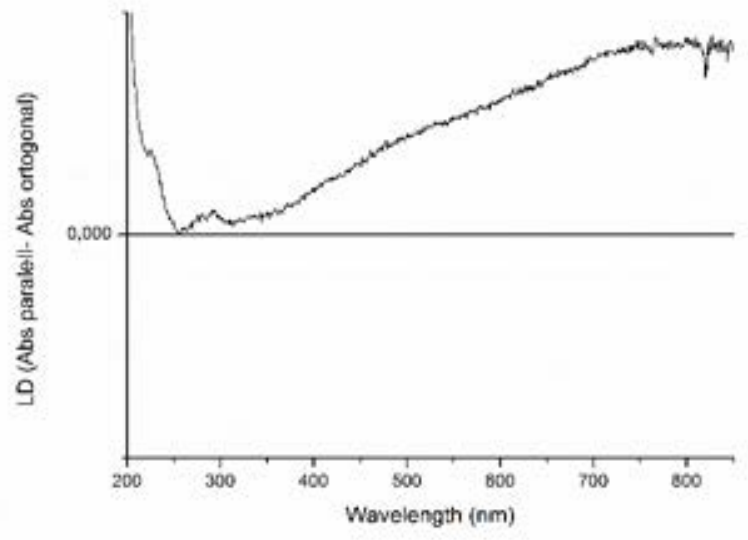

Figure 17 Linear dichroism (LD) spectrum PEDOT-S onto hen egg white lysozyme (HEWL) amyloid like fibrils. [Unpublished results]

Since the preservation of the desired functionality, in this case conductivity, is one of the cornerstone in successful biotemplating, we needed to examine the electronic behavior. To maximize the decorating layer we added a large excess of PEDOT-S to the amyloid fibrils but were able to remove the unbound polymer by subsequent centrifugation and washing of the PEDOT-S:Amyloid complex, a process depicted in Figure 18.

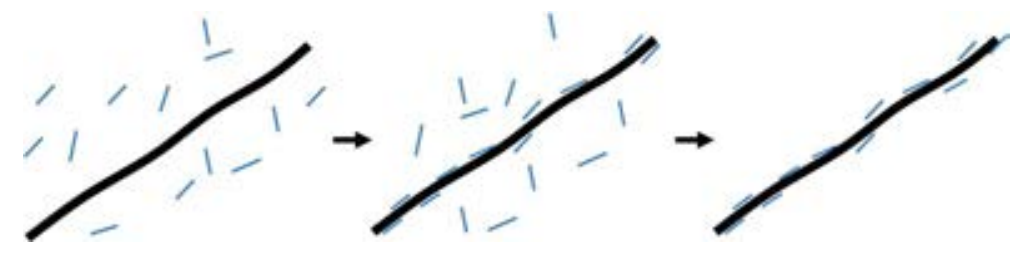

Figure 18 Schematic image of the self-assembly process with the amyloid fibril in black and PEDOT-S in blue. As the PEDOT-S attaches to the amyloid fibril and finally the fibril is coated with conducting material. Using centrifugation it is also possible to remove all non-attached PEDOT-S.

Since most analyzing techniques are based on macroscopic conductance of a material and we wanted to eliminate the possibility that the conductance was due to free, un-bound PEDOT-S we turned to measuring the microscopic conductivity using conducting atomic force microscopy (C-AFM). In Figure 19 the lateral C-AFM setup is visualized where the probe tip is, as in the case of standard AFM not only measuring the topography, but also the current flowing through a circuit. 


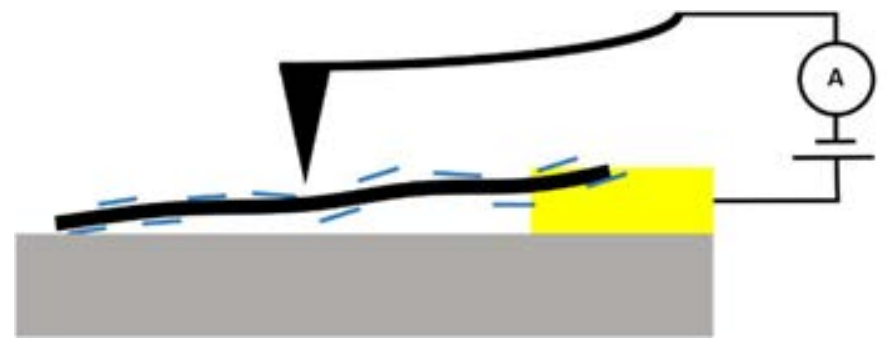

Figure 19 Sketch of a lateral C-AFM setup where the decorated fibrils are placed at the edge between the insulating substrate (grey) and an electrode (yellow). A bias voltage is applied between the tip and the electrode and the current through the circuit is measured.

The resulting current and topography images as seen in Figure 20 reveal that the current and height mappings do indeed overlap leading to two major conclusion; firstly the insulating amyloid fibrils are in fact decorated by a conducting material, meaning PEDOT-S is successfully biotemplated onto the amyloid fibrils. Secondly, there is no significant background conductance, meaning the procedure (as depicted in Figure 18) to remove unbound PEDOT-S has been successful.
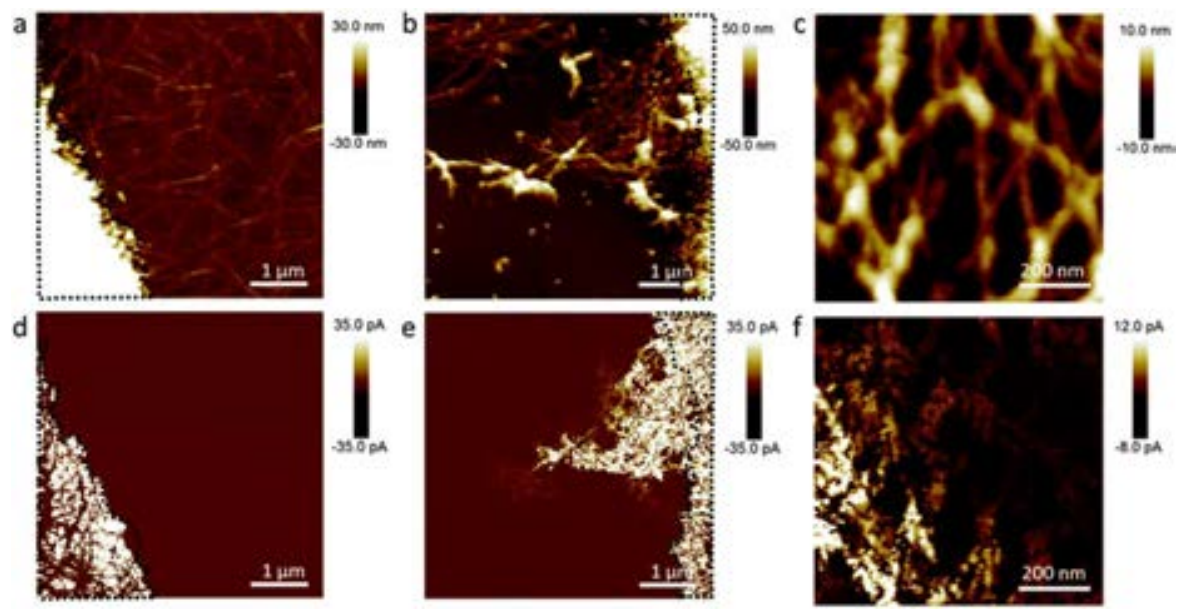

Figure 20 AFM insulin amyloid fibrils. a)-c) show toppgraphy and d)-f) show current mapping. Uncoated fibrils a) show no conductivity as seen in d). Coated fibrils $b$ ) on the other hand do show conductance as seen in e). A close-up topography image c) with corresponding current mapping f) reveals a correlation between structure and conductance. Reproduced with permission from ${ }^{31}$.

With knowledge of the decoration procedure and the alignment of the conducting polymer onto amyloid fibrils we wanted to expand the concept to decoration of helical insulin amyloid superstructures ${ }^{65}$. Helical superstructures have previously been reported and extensively studied by Wojciech Dzwolaks group at the university of Warzaw ${ }^{66-69}$. In short dissolved insulin are turned into chiral superstructures by fibrillating the insulin molecules in the presence of high salt concentration and vortexing the sample. The resulting structure has previously been shown to create an induced circular dichroism signal of thioflavin T (ThT), a planar non chiral molecule. This has been taken as a proof 
that ThT arrange itself onto the chiral superstructure. In Figure 21 the general principle is shown where native insulin is denatured in acid in the presence of salt under agitation. Depending on the stirring direction during the formation of the superstructures it is possible to create structures with either right-hand or left hand twist. Finally; using a similar approach as for amyloid fibrils, PEDOT-S was used to decorate the superstructures.

a

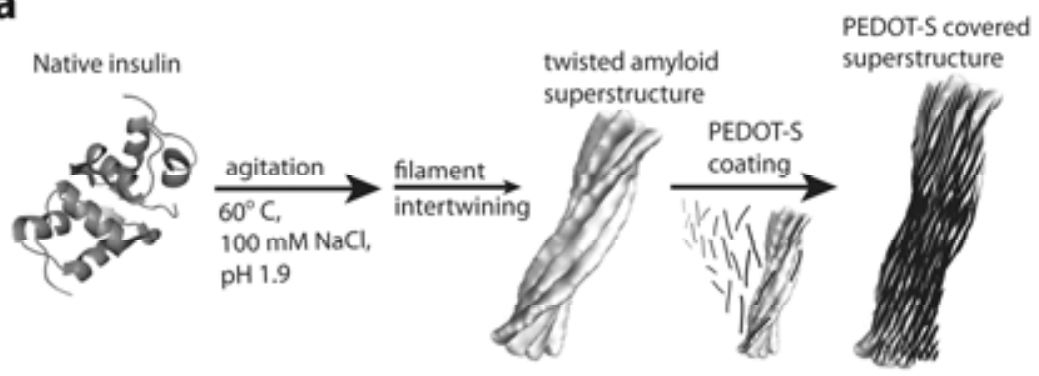

Figure 21.The preparation route where native insulin is denatured in acid in the presence of salt and agitation. This procedure yields a twisted amyloid superstructure. A superstructure which could decorated with PEDOT-S creating a PEDOT-S covered superstructure. Reproduced with permission from ${ }^{65}$.

Circular dichroism was used to verify the alignment of PEDOT-S onto the superstructure with the results shown in Figure 22. Naked superstructures (labeled ICD- and ICD+) do only show a circular dichroism in the UV-region but none in the visible region. PEDOT$S$ coated superstructures (labeled ICD- PEDOT-S and ICD+ PEDOT-S) show similar behavior in the UV-region indicating the superstructures are still intact and showe a strong induced circular dichroism signal in the visible spectra. Due to the similarity with the absorbance of PEDOT-S (as seen in figure Figure 11) we conclude this induced CDsignal is due to the helical arrangement of PEDOT-S onto the superstructures.

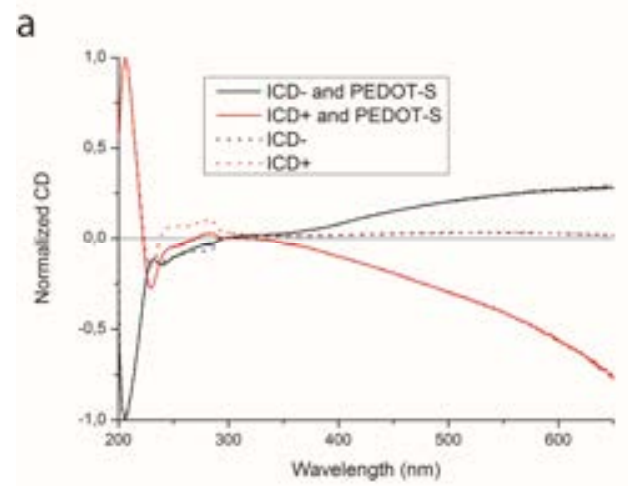

Figure 22 Circular dichroism (CD) spectrum of insulin amyloid like fibrillary superstructure with and without PEDOT-S. ICD- and ICD+ indicate the predominant helicity of the uncoated superstructures. The dotted lines indicate the signal from non-coated structures and whole lines signal from coated structures. Adapted with permission from ${ }^{65}$. 
However, native superstructures are only stable in high salt conditions, which screen off the mutual repulsion between the positively charged fibrils. As an unexpected side effect of the decoration procedure the superstructures were stabilized. Figure 23 show the result of an experiment where the decoration of superstructures are a performed after (Figure 23a-c) dilution in water. The effect of removing the screening salt concentrations is revealed in scanning electron microscopy imaging where the superstructure are disrupted (Figure 23a-b). The corresponding CD spectrum show that the ability to arrange PEDOT$\mathrm{S}$ in a chiral manner is lost (Figure 23c). In the control experiment (Figure 23d-f) where PEDOT-S was added prior to water dilution show intact structures (Figure 23d-e) with retained chiral organization as detected by circular dichroism (Figure 23f).
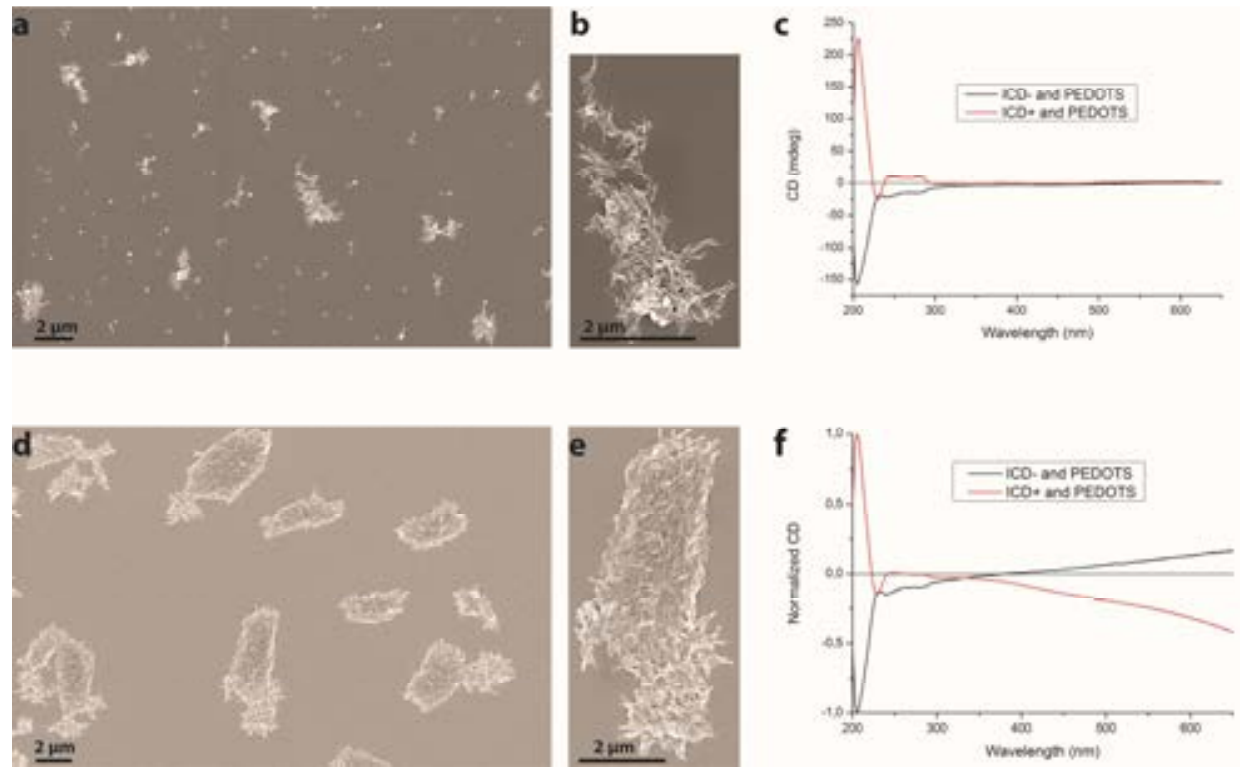

Figure 23 Stabilizing effect of the decoration procedure. a)-c) show the effect of diluting the structures in water prior to exposure to PEDOT-S. d)-f) show the effect of diluting the structures in water after the exposure to PEDOT-S. Reproduced with permission from ${ }^{65}$.

Silk-like materials share common features with amyloid like fibrils as these structures are in predominantly beta-sheet conformation. The macroscopic silk fibers could be coated by simply immersing them into a PEDOT-S solution and successful decoration could be verified visually as the fibers turned dark. The decoration could also be detected as an increased conductivity, by simple conductance measurements of a fiber stretched out between two electrodes (see Figure 24). In PAPER I artificial spider silk was used as a biotemplate for PEDOT-S and it was found that low $\mathrm{pH}$, high concentration of the polymer solution and elevated temperature was necessary for successful decoration. The low $\mathrm{pH}$ would ensure the protonation of the amino acids and thus give the polypeptide a net positive charge complementary to the negative charge of the conjugated polymer. The temperature and higher concentration of the coating material was probably necessary to be able to penetrate the bulk of the fibril as visible in Figure $24 .{ }^{32}$ A similar approach have later been applied to bombyx moori $\operatorname{silk}^{35}$. 

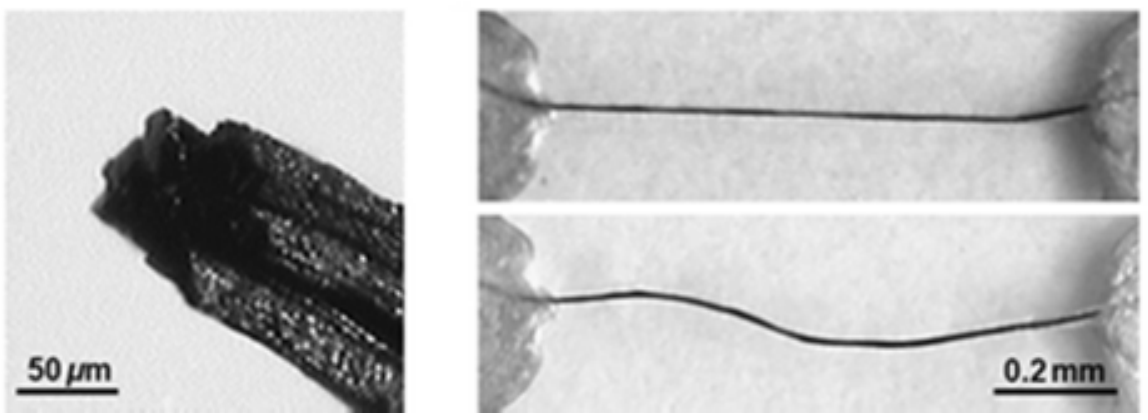

Figure 24 PEDOT-S coated artificial spider silk fiber.Left: Cross-cut through the fiber revealing bulk decoration. Right: Decorated fiber between electrodes. Adapted with permission from ${ }^{32}$.

Although only few attempts have been made to characterize the nature of the interaction between the peptide structures and PEDOT-S it is assumed that it is an entropy driven process as discussed in the theory section. As Muller et al noted the $\mathrm{pH}$ of the reactions was important, as the charge of the biomolecule was increasingly positive with lower $\mathrm{pH}^{32}$. Since the $\mathrm{pKa}$ of PEDOT-S is around 2 a strong mutual coulombic attraction is expected between the sulfonic acid sidechains of PEDOT-S and the protonated arginine, lysine and histidine amino acids of the protein structures. There are, however, indications that other forces are also contributing to the complex formation; poly(thiophenic acid) PTAA show structural (Figure 25) similarities with PEDOT-S and have the ability to bind strongly to protein structures ${ }^{32,58}$ but since the side group is acetic acid, the reaction takes place at neutral $\mathrm{pH}$ where the charge of the protein structure actually is slightly negative. A possible explanation could be interaction between the hydrophobic backbone of the conjugated polymer and hydrophobic pockets in the protein structure.

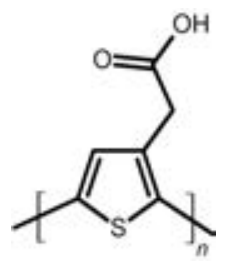

Figure 25 PTAA structure. The thiophene backbone has acetic acid sidegroup enabling water solubility and electrostatic interaction with charged biomolecules. 


\section{DNA scaffolds}

Using DNA as biotemplate is inherently difficult due to the low stability of the molecule, especially at non-physiological conditions. DNA is a highly charged polyanion meaning any interaction with the poly-anionic PEDOT-S is unlikely due to mutual columbic repulsion. To overcome this incompability two different approaches were used. Firstly, as described in PAPER II, divalent cations was used as charge bridges which could link the phosphates of the DNA with the sulphonate acids of PEDOT-S (Figure 26).

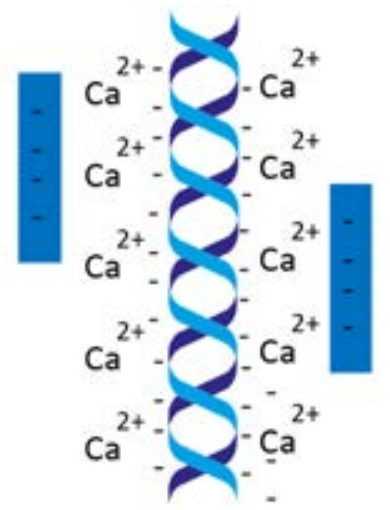

Figure 26 Naïve depiction of the charge bridging effect of PEDOT-S onto DNA. The divalent cations are acting as counter-ions for the phosphates of the DNA and the sulphonates of PEDOT$S$ thus eliminating the mutual electrostatic repulsion between the polyions.

The decoration of PEDOT-S onto very long lambda-DNA chains was possible to verify by quenching studies and stretching the PEDOT-S:DNA between microelectrodes (Figure 27). 
(a)

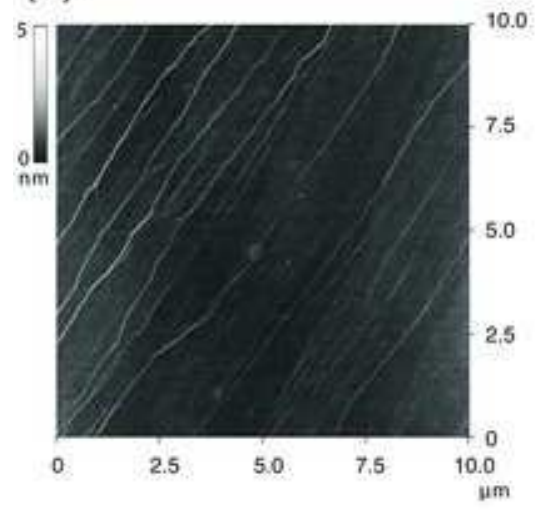

(b)

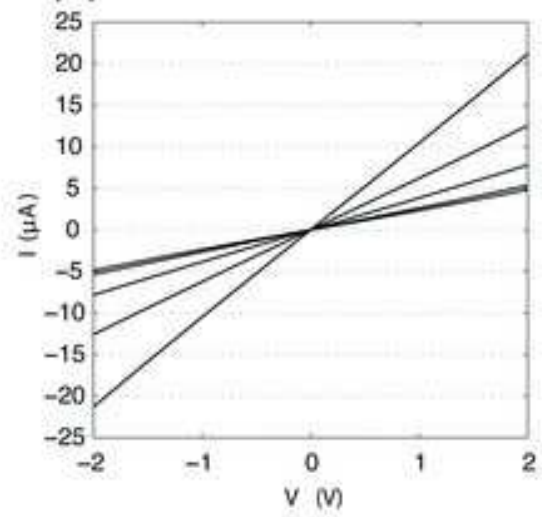

\section{(c)}

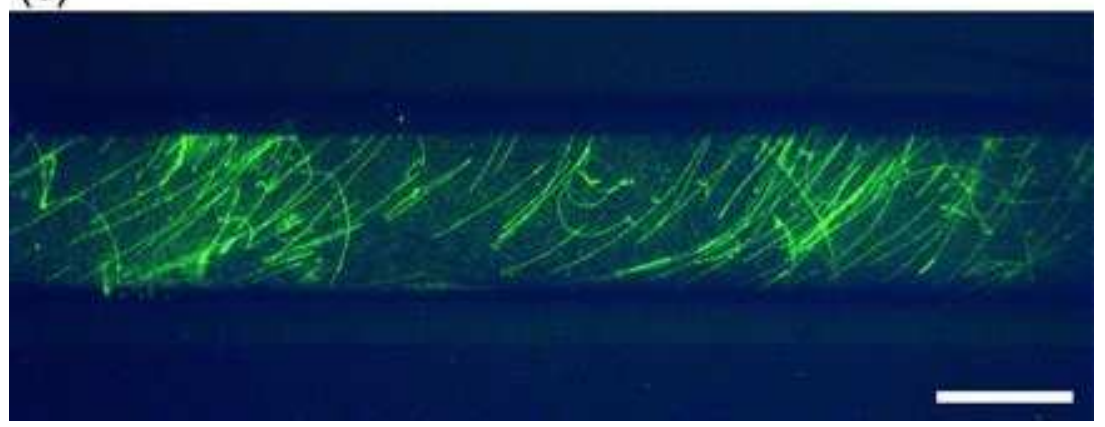

Figure 27 a) AFM micrograph of PEDOT-S decorated lambda DNA stretched out on a surface. $b$ ) I-V curve for several devices of PEDOT-S:Ca:DNA complex stretched between microelectrodes. $c$ ) Fluorescent image of YOYO stained DNA (vertical green lines) stretched out between microelectrodes (horizontal dark bars) Reproduced with permission from ${ }^{36}$.

The use of divalent cations is, however, complicated by the risk of crosslinking PEDOT$\mathrm{S}$ with itself causing aggregation of unwanted conjugated material in the solution while decorating. DNA can, however, be stabilized by complexing with a surfactant. One of the most successful approaches is the use of cetyltrimethylammonium (CTMA) (Figure 28d) where the positively charged ammonium group of the surfactant binds onto the negatively charged phosphate backbone of DNA (Figure 28a-b.) 
a

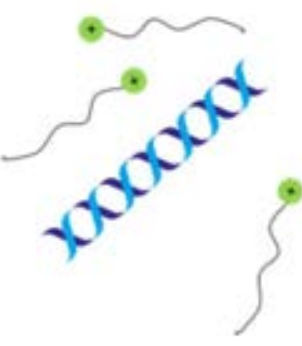

d
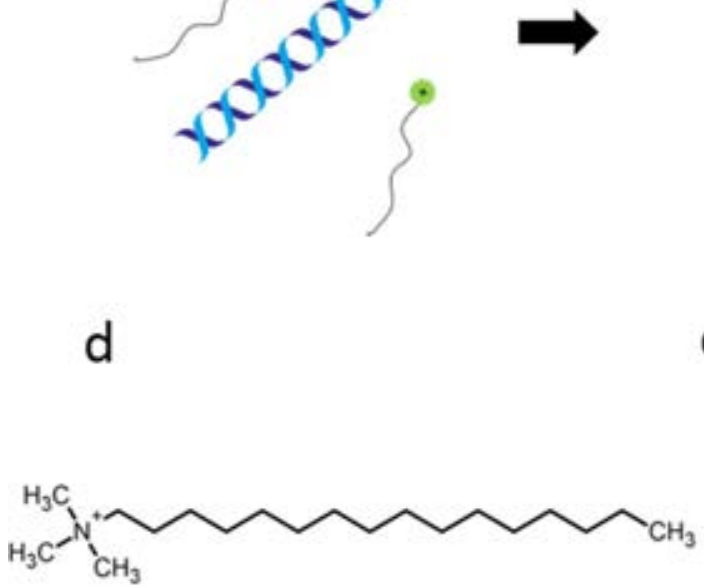

b

C
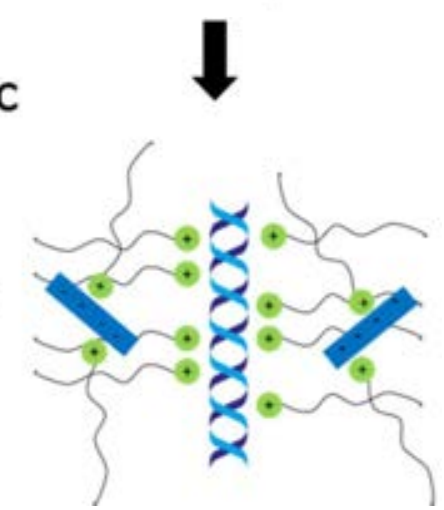

Figure 28 Nä̈ve scheme of DNA:CTMA:PEDOT-S complexation. a) DNA and CTMA are water soluble but will self-assemble into water insoluble complexes as depicted in b). c) When PEDOT-S is added to the DNA:CTMA complex CTMA and PEDOT-S will interact, most likely form a CTMA:PEDOT-S complex although the role of DNA is unclear. d) Molecular structure of CTMA.

The DNA:CTMA complex is insoluble in aqueous media partly due to loss of net charge, as the negative charge of the phosphoric backbone is neutralized by the positive amine groups of the surfactant, partly due the creating of a shell of hydrophobic hydrocarbon tails of the surfactant surrounding the DNA. The complex is soluble in non-aqueous solvent such as ethanol where its stability is greatly enhanced ${ }^{70}$ The solution processable DNA:CTMA complex have been used as a matrix for functional agents such as fluorescent dyes ${ }^{71-73}$ and conducting materials ${ }^{74}$. Although the DNA chain condensates into particles during the complexation with CTMA and lose much of its stretchable form the inclusion of PEDOT-S into such a matrix is intriguing and the idea was investigated in PAPER VI. The the native DNA:CTMA complex have been extensively used as a hole transport layer and electron blocking layer in electro-optical devices due to the very deep HOMO (5.4 $\left.4^{75}-5.6^{76,77} \mathrm{eV}\right)$ and very shallow LUMO $\left(0.9^{76}-1.3^{77} \mathrm{eV}\right)$. When PEDOT-S was added to the DNA:CTMA complex PEDOT-S most likely interacted with the ammonium head of the CTMA (as depicted in Figure 28c) due to mutual electrostatic attraction. Although exact mechanism is unclear the new material show some very interesting properties where the HOMO shifts from 4.8 for pure PEDOT-S to 4.2 for the new material thus making it possible to use as an electron transport material. An organic 
photovoltaic (OPV) device with the new material as an interlayer is depicted in Figure 29a. The content of PEDOT-S in the complex is essential for the function of the material as seen in Figure 29b showing I-V-curves for devices with varying ratios of PEDOT-S to DNA. As seen low ratio will essentially destroy the performance of the OPV device whereas the optimal ratio will yield a performance comparable to evaporated $\mathrm{LiF}$.
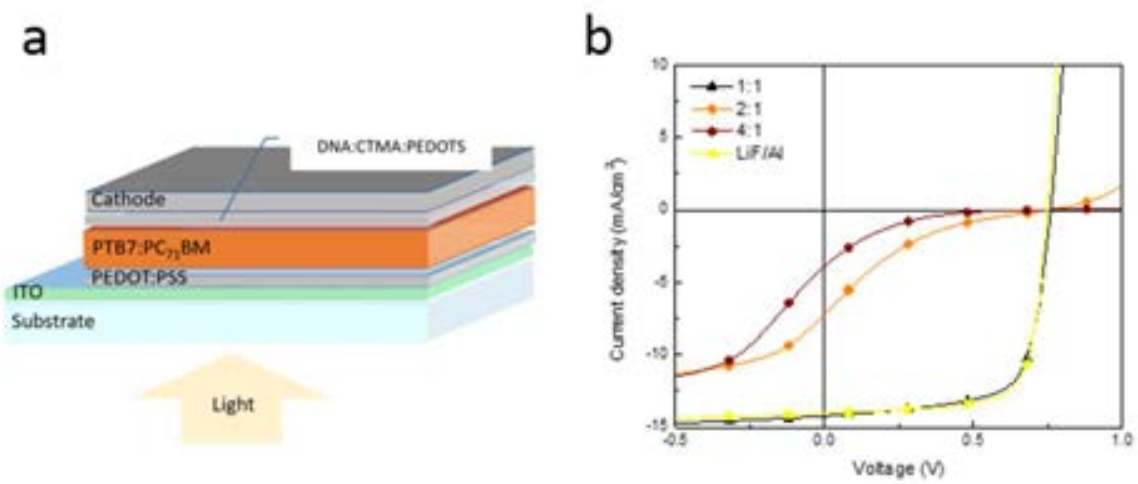

Figure 29 DNA:CTMA:PEDOT-S complex as electron transport layer in OPV. a) The structure of the solar cell where the DNA:CTMA:PEDOT-S complex is spin coated onto the active layer acting as an electron transport layer. $b)$ The resulting I-V curve for devices with complexes where the ratio of DNA to PEDOT-S has been varied. As noted devices with a low content of PEDOT-S (4:1 and 2:1) did not work. For optimal DNA to PEDOT-S ratio (1:1) the electron transport layer works as good as the reference (evaporated LiF). 


\section{Liposome scaffold}

Interaction between water soluble polymers and liposomes is not straight-forward as they simply do not mix. It was, as presented in PAPER III, possible to tune the solubility of PEDOT-S by complexing the polymer with alkyl-amines. Alkyl amines are amphiphilic surfactants, with a similar structure to lipids; meaning a polar head and a less water soluble tail. The positive charged amine can interact with the sulphonate sidechains of PEDOT-S creating a new complex; PEDOT-S:alkylamine which is insoluble in aqueous media, as illustrated in Figure 30a and b. As the sulphonate sidechains are acting as dopant the concentration, $\mathrm{pH}$ and type of amine was carefully chosen to preserve the metallic properties of the conjugated polymer.

a
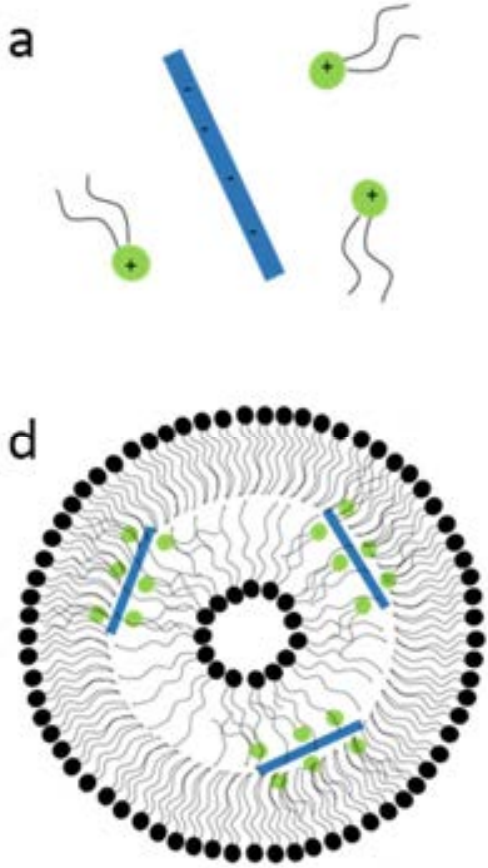

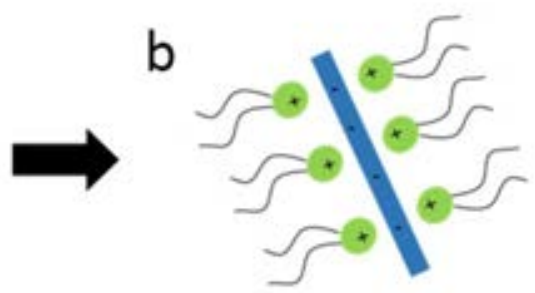

C
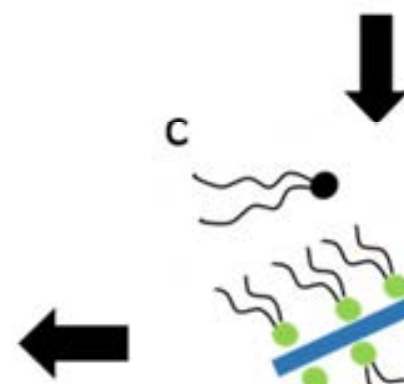

Figure 30 Self-assembly of PEDOT-S into liposomes. a)-b) Naïve illustration of the nanoassembly of alkyl-amine surfactants (green) with PEDOT-S (blue). c)-d) Upon mixing with phospholipids and addition of aqueous media creates liposomes with integrated PEDOT-S complex.

The complex is soluble in various non-polar solvent making it possible to blend with lipids and thus to be incorporated into liposomes. As PEDOT-S:alkylamine complex and phospholipids are dispersed in water, liposomes will form spontaneously by the hydrophobic effect as depicted in Figure 30c-d. The exact arrangement of the conjugated system with the liposome is not known although fluorescent quenching studies indicate PEDOT-S is located close to the lipid bilayer surrounding the liposome. As liposomes can interact and fuse with other lipid bilayers these results pave the way for true bioorganic electronics where conducting elements inserted the cell membrane could be 
addressed by extracellular electrodes. Our initial results show that the mere insertion of a conducting complex in the cell membrane of frog egg cells have significant effects on ion channels (Figure 31), although the exact nature of the interaction hitherto is unknown.
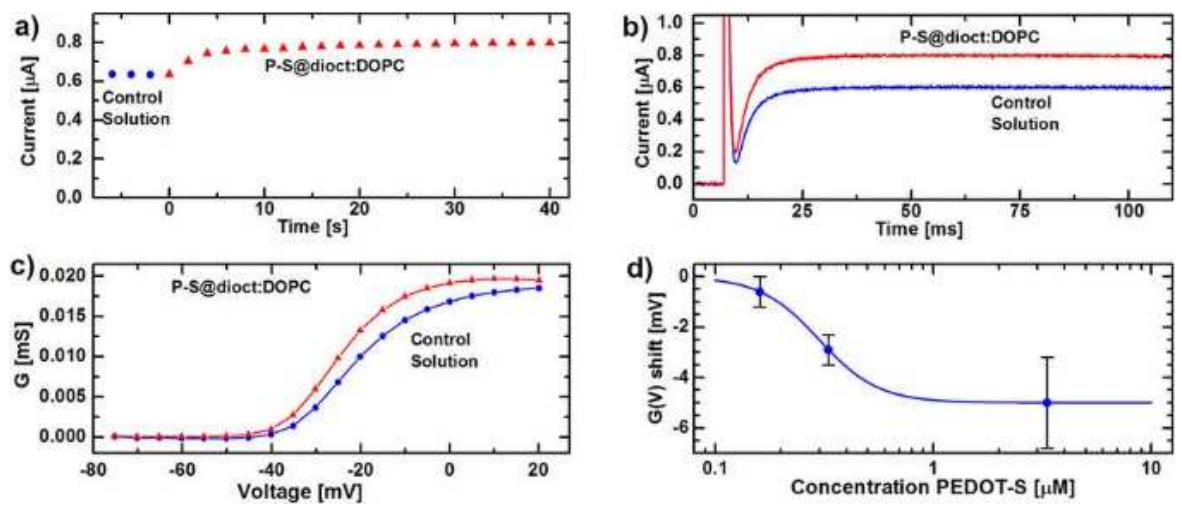

Figure 31 Effect of PEDOS-S liposomes (here labeled P-S@dioct:DOPC) on frog egg cells as measured using two-electrode voltage-clamp technique. Addition of PEDOT-S:liposomes increase a) the steady-state current and b) the transient current traces when shifting the holding voltage (from -80mVto -20 mV) and c) shifts the voltage dependence of the ion channels. d) Increasing concentrations of PEDOT-S:liposomes induce a larger shift until a saturation niveau. Reproduced with permission from ${ }^{37}$. 


\section{Carbohydrate scaffold}

As mentioned before carbohydrate structures are extremely abundant in nature and expanding biotemplating into this class of material is of great interest. Kamata et al has described how coiled cellulose structures from lotus roots can be turned into $\mathrm{THz}$ antennas ${ }^{8}$ and Agarwal et al has used a layer by layer approach to coat cellulose structure with conducting polymers ${ }^{78}$. Inspired by these works we pursued a path in PAPER VII where helical cellulose based structures were coated with PEDOT-S in a two-step process as depicted in Figure 32. Since native cellulose only has a weak negative surface charge it is not suitable for complex formation with the negatively charged PEDOT-S. However, the surface charge changes sign by submerging the coils in the polycation polyethyleneimine (PEI). In the second step the coil is submerged in PEDOT-S.
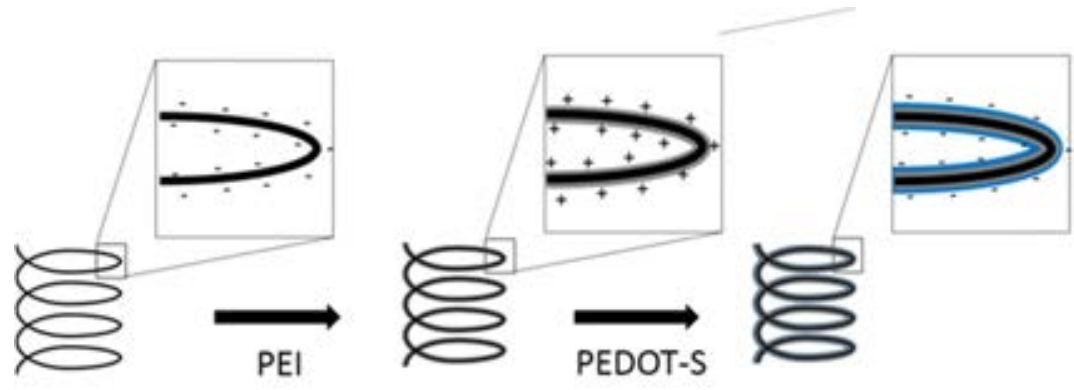

Figure 32 Two step process of coating helical cellulose structures with PEDOT-S. The polycationic PEI is added to the negatively charged cellulose based coil structure effectively reversing the surface charge of the coil. As polyanionic PEDOT-S is added to the PEI-coated coil it readily decorated the helical structure.

Investigation with SEM reveal the intricate coiled like microstructure (Figure 33a) which is preserved after the decoration. The decorated material show significant conductivity and as it is well known that conducting coils can be seen as small antennas. Figure $33 \mathrm{~b}$ show the absorbance in in the submillimeter range (corresponding to $\mathrm{THz}$ ) which is likely since the dimensions of the coil are in the $10-100 \mu \mathrm{m}$ range (Figure 33c). 
a

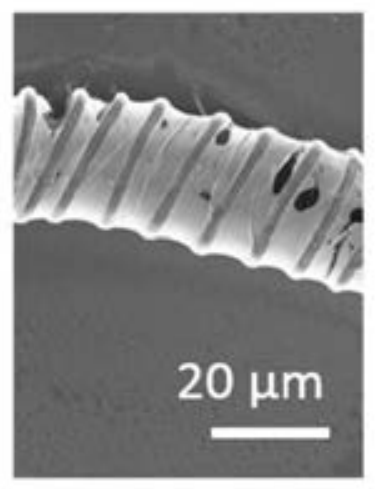

b

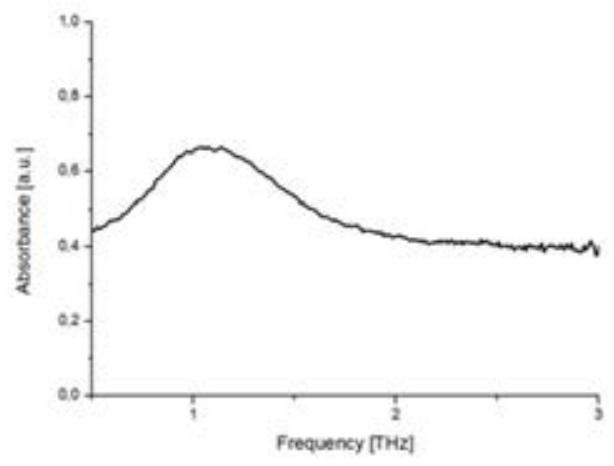

C 10-1000 turns

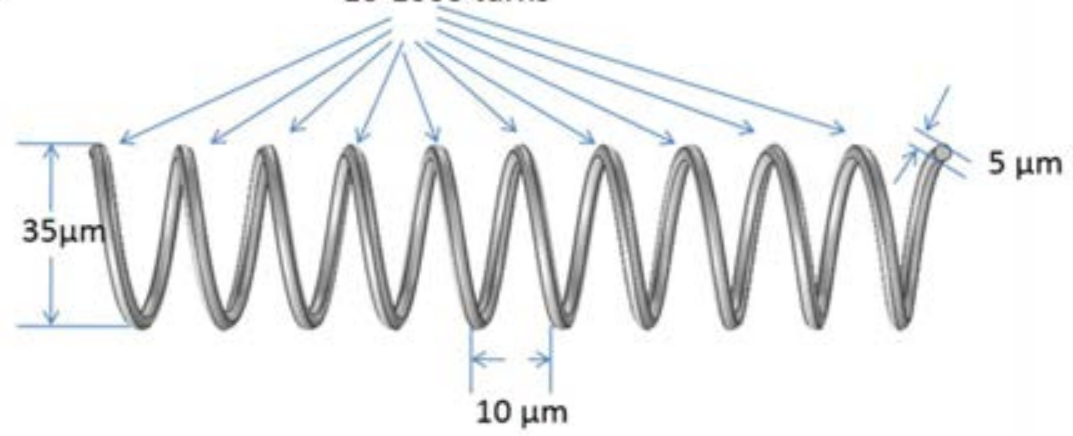

Figure 33 Celery coils. a) SEM image of native celery coil. b) THz absorbance spectrum of PEDOT$S$ decorated celery coil. c) Geometrical dimensions of the coil. 


\section{CONCLUSIONS AND FUTURE OUTLOOK}

The route of self-assembled biotemplating is a promising one. Future work will focus on finding or creating biotemplates with low structural variability. The functional polymers also needs attention in order to increase conductivity and, possibly, add more specificity in their interactions with the templates.

The aim of our projects and the focus of this thesis have never been to construct electronic devices with a specific application. The biomolecular scaffold we have used, be it protein based fibers, DNA, liposomes or cellulose, are far too crude and unordered for any practical applications. The functionalizing agent, the conducting molecule we have used, PEDOT-S have relative low conductivity, and is poorly characterized. The scaffold and functionalizing agent are to be seen as model systems to show a possible generic approach to create biotemplated hybrid materials. As we started out on this project decorating biomolecular structures with PEDOT-S was an already well established concept but limited to interactions between a polyanionic polymer and positively charged structures. To expand the concept to structures having a negative charge, such as DNA or cellulose, the obvious choice would be a positively charged polymer and in the case of non-charged systems, such as lipids, the most straightforward solution would be to use a conjugated polymer soluble in non-aqueous solvent. Such polymers are, however, rare and in lieu of such conjugated systems we have expanded the concept by using a ubiquitous conjugated polymer, PEDOT-S, and by tweaking the self-assembly conditions we have found ways of decorating biomolecular scaffold regardless of charge and hydrophobicity.

In paper I, IV and V we investigated protein based scaffolds; artificial spider silk, insulin amyloid like fibrils, and superstructures based on amyloid like fibrils respectively. The main finding in paper I was the expansion of the concept of self organization of conjugated polymers to macroscopic systems. As these protein fibers have shown remarkable mechanical and biological activity the introduction of conductive functionality in future developments would probably be of great value. In paper IV and $\mathrm{V}$ the use of conducting AFM was instrumental in showing, for the first time, that the conductivity was, in fact, confined to the intended nano- and micro-structures. A novel procedure was developed to maximize the conductive coating as well as eliminate any conductive species unassociated with these structures, The close interaction between PEDOT-S and the protein wire was also investigated in paper II using energy transfer between an embedded dye inside the protein wire and the conjugated system, paving the way further studies on the intricate interactions between conjugated systems and amyloids. In paper V the well-ordered self-assembly of PEDOT-S onto beta-sheet based material was shown to induce optical properties as well. Future development would include these stable hybrid structures to create $\mathrm{THz}$ resonators.

In paper II and VI the interaction between PEDOT-S and DNA was investigated. Although combining two anionic species was not straightforward we used divalent ions (paper II) or surfactants (paper VI) to bridge or eliminate the mutual columbic repulsion. In paper II these findings resulted in conducting nanowires and electrochemical transistors. In paper VI the procedure resulted in a stable work function modification which could be utilized in photovoltaic devices. Expanding these concept to DNA origami would be a natural future development. 
In paper III the interaction between PEDOT-S and liposomes was elucidated. Complexing the highly charged PEDOT-S with structures assembled by the hydrophobic effect was only possible by complexing the polyelectrolyte with a surfactant effectively creating a species soluble in organic solvent. Using this path it was possible to insert the conjugated polymer into liposomes and these conducting liposomes showed a significant effect on ion channels in cell studies. Future development of this concept would include further studies in order to elucidate the nature of the interaction between the conjugated system and the ion channels.

In paper VII the concept was further expanded to a cellulose based system. By introducing a positively charged material to the negatively charged cellulose surface it was possible to dress helical shaped cellulose with PEDOT-S paving the way for self-assembled $\mathrm{THz}$ resonators. 


\section{REFERENCES}

1. Khoo, Z. X. et al. 3D printing of smart materials: A review on recent progresses in 4D printing. Virtual Phys. Prototyp. 10, 103-122 (2015).

2. Kuzyk, A. et al. DNA-based self-assembly of chiral plasmonic nanostructures with tailored optical response. Nature 483, 311-4 (2012).

3. Schreiber, R. et al. Chiral plasmonic DNA nanostructures with switchable circular dichroism. Nat. Commun. 4, 2948 (2013).

4. Schreiber, R. et al. Hierarchical assembly of metal nanoparticles, quantum dots and organic dyes using DNA origami scaffolds. Nat. Nanotechnol. 9, 74-8 (2014).

5. Shaw, A. et al. Spatial control of membrane receptor function using ligand nanocalipers. Nat. Methods 11, 841-6 (2014).

6. Braun, E., Eichen, Y., Sivan, U. \& Ben-Yoseph, G. DNA-templated assembly and electrode attachment of a conducting silver wire. Nature 391, 775-8 (1998).

7. Kamata, K. et al. Spirulina-Templated Metal Microcoils with Controlled Helical Structures for THz Electromagnetic Responses. Sci. Rep. 4, 4919 (2014).

8. Kamata, K. et al. Fabrication of Left-Handed Metal Microcoil from Spiral Vessel of Vascular Plant. Adv. Mater. 23, 5509-5513 (2011).

9. Dong, L. et al. Synthesis, manipulation and conductivity of supramolecular polymer nanowires. Chemistry 13, 822-8 (2007).

10. Nickels, P., Dittmer, W. U., Beyer, S., Kotthaus, J. P. \& Simmel, F. C. Polyaniline nanowire synthesis templated by DNA. Nanotechnology 15, 1524-1529 (2004).

11. Meier, C., Lifincev, I. \& Welland, M. E. Conducting core-shell nanowires by amyloid nanofiber templated polymerization. Biomacromolecules 16, 558-563 (2015).

12. Watson, S. M. D., Pike, A. R., Pate, J., Houlton, A. \& Horrocks, B. R. DNAtemplated nanowires: morphology and electrical conductivity. Nanoscale 6, 4027-37 (2014).

13. Bucur, C. B., Sui, Z. \& Schlenoff, J. B. Ideal mixing in polyelectrolyte complexes and multilayers: Entropy driven assembly. J. Am. Chem. Soc. 128, 13690-1 (2006).

14. Salzmann, I., Heimel, G., Oehzelt, M., Winkler, S. \& Koch, N. Molecular Electrical Doping of Organic Semiconductors: Fundamental Mechanisms and Emerging Dopant Design Rules. Acc. Chem. Res. 49, 370-378 (2016).

15. Patil, A. O. et al. Self-doped conducting polymers. Synth. Met. 20, 151-159 
(1987).

16. Jager, E. W. H., Smela, E., Inganäs, O. \& Lundström, I. Polypyrrole microactuators. Synth. Met. 102, 1309-1310 (1999).

17. Isaksson, J. et al. Electronic control of $\mathrm{Ca} 2+$ signalling in neuronal cells using an organic electronic ion pump. Nat. Mater. 6, 673-679 (2007).

18. Erlandsson, P. G. \& Robinson, N. D. Electrolysis-reducing electrodes for electrokinetic devices. Electrophoresis 32, 784-790 (2011).

19. Nilsson, D. et al. Bi-stable and Dynamic Current Modulation in Electrochemical Organic Transistors. Adv. Mater. 14, 51-54 (2002).

20. Pei, Q., Zuccarello, G., Ahlskog, M. \& Inganäs, O. Electrochromic and highly stable poly(3,4-ethylenedioxythiophene) switches between opaque blue-black and transparent sky blue. Polymer (Guildf). 35, 1347-1351 (1994).

21. Lee, S. H., Park, H., Son, W., Choi, H. H. \& Kim, J. H. Novel solution-processable, dedoped semiconductors for application in thermoelectric devices. J. Mater. Chem. A 2, 13380-13387 (2014).

22. Bubnova, O. et al. Optimization of the thermoelectric figure of merit in the conducting polymer poly(3,4-ethylenedioxythiophene). Nat. Mater. 10, 429433 (2011).

23. Nordén, B. \& Kurucsev, T. Analysing DNA complexes by circular and linear dichroism. J. Mol. Recognit. 7, 141-155 (1994).

24. Bäcklund, F. G., Wigenius, J., Westerlund, F., Inganäs, O. \& Solin, N. Amyloid fibrils as dispersing agents for oligothiophenes: control of photophysical properties through nanoscale templating and flow induced fibril alignment. $J$. Mater. Chem. C 2, 7811 (2014).

25. Ouyang, L., Musumeci, C., Jafari, M. J., Ederth, T. \& Inganäs, O. Imaging the Phase Separation between PEDOT and Polyelectrolytes during Processing of Highly Conductive PEDOT:PSS Films. ACS Appl. Mater. Interfaces 7, 19764-19773 (2015).

26. Hamedi, M., Karabulut, E., Marais, A., Herland, A. \& Nyström, G. Nanocellulose aerogels functionalized by rapid layer-by-layer assembly for high charge storage and beyond. Angew. Chemie - Int. Ed. 52, 12038-12042 (2013).

27. Stéphan, O. et al. Electrochemical behaviour of 3, 4-ethylenedioxythiophene functionalized by a sulphonate group. Application to the preparation of poly(3, 4-ethylenedioxythiophene) having permanent cation-exchange properties. $J$. Electroanal. Chem. 443, 217-226 (1998).

28. Karlsson, R. H. et al. Iron-Catalyzed Polymerization of Alkoxysulfonate- 
Functionalized 3,4-Ethylenedioxythiophene Gives Water-Soluble Poly(3,4ethylenedioxythiophene) of High Conductivity. Chem. Mater. 21, 1815-1821 (2009).

29. Persson, K. M. et al. Electronic Control of Cell Detachment Using a Self-Doped Conducting Polymer. Adv. Mater. 23, 4403-4408 (2011).

30. Elschner, A., Kirchmeyer, S., Lovenich, W., Merker, U. \& Reuter, K. PEDOT: Principles and Applications of an Intrinsically Conductive Polymer. Chemical Communications (CRC Press, 2010). doi:10.1201/b10318-10

31. Elfwing, A., Bäcklund, F. G., Musumeci, C., Inganäs, O. \& Solin, N. Protein nanowires with conductive properties. J. Mater. Chem. C 3, 6499-6504 (2015).

32. Müller, C. et al. Functionalisation of recombinant spider silk with conjugated polyelectrolytes. J. Mater. Chem. 21, 2909-2915 (2011).

33. Hamedi, M., Wigenius, J., Tai, F.-I., Björk, P. \& Aili, D. Polypeptide-guided assembly of conducting polymer nanocomposites. Nanoscale 2, 2058-61 (2010).

34. Hamedi, M., Herland, A., Karlsson, R. H. \& Inganäs, O. Electrochemical devices made from conducting nanowire networks self-assembled from amyloid fibrils and alkoxysulfonate PEDOT. Nano Lett. 8, 1736-40 (2008).

35. Müller, C. et al. Woven electrochemical transistors on silk fibers. Adv. Mater. 23, 898-901 (2011).

36. Hamedi, M., Elfwing, A., Gabrielsson, R. \& Inganäs, O. Electronic polymers and DNA self-assembled in nanowire transistors. Small 9, 363-8 (2013).

37. Johansson, P. K. et al. Electronic polymers in lipid membranes. Sci. Rep. 5, 11242 (2015).

38. Lee, J. et al. Long-Term Stable Recombination Layer for Tandem Polymer Solar Cells Using Self-Doped Conducting Polymers. ACS Appl. Mater. Interfaces 8, 6144-6151 (2016).

39. Cai, W. et al. Self-doped conjugated polyelectrolyte with tuneable work function for effective hole transport in polymer solar cells. J. Mater. Chem. A 4, 1567015675 (2016).

40. Cutler, C. A., Bouguettaya, M., Kang, T.-S. \& Reynolds, J. R. AlkoxysulfonateFunctionalized PEDOT Polyelectrolyte Multilayer Films: Electrochromic and Hole Transport Materials. Macromolecules 38, 3068-3074 (2005).

41. Persson, K. M. et al. Matrix Addressing of an Electronic Surface Switch Based on a Conjugated Polyelectrolyte for Cell Sorting. Adv. Funct. Mater. 25, 7056-7063 (2015). 
42. Persson, K. M. et al. Electronic control over detachment of a self-doped watersoluble conjugated polyelectrolyte. Langmuir 30, 6257-66 (2014).

43. Zeglio, E. et al. Conjugated Polyelectrolyte Blends for Electrochromic and Electrochemical Transistor Devices. Chem. Mater. 27, 6385-6393 (2015).

44. Hamedi, M., Tvingstedt, K., Karlsson, R. H., Åsberg, P. \& Inganäs, O. Bridging dimensions in organic electronics: Assembly of electroactive polymer nanodevices from fluids. Nano Lett. 9, 631-635 (2009).

45. Cutler, C. A., Bouguettaya, M., Kang, T.-S. \& Reynolds, J. R. AlkoxysulfonateFunctionalized PEDOT Polyelectrolyte Multilayer FilmsElectrochromic and Hole Transport Materials .pdf. Macromolecules 38, 3068-3074 (2005).

46. Reches, M. \& Gazit, E. Casting Metal Nanowires Within Discrete Self-Assembled Peptide Nanotubes. Science (80-. ). 300, 625-627 (2003).

47. Adler- Abramovich, L. et al. Thermal and Chemical Stability of Diphenylalanine Peptide Nanotubes:Implications for Nanotechnological Applications. Langmuir 22, 1313 (2006).

48. Andersen, K. B., Castillo-Leon, J., Hedström, M. \& Svendsen, W. E. Stability of diphenylalanine peptide nanotubes in solution. Nanoscale 3, 994-998 (2011).

49. Waugh, D. F. A fibrous modification of insulin. I. The heat precipitate of insulin. J. Am. Chem. Soc. 68, 247-50 (1946).

50. D., W. \& Crick, F. H. C. Molecular Structure of Nucleic Acids: A Structure for Deoxyribose Nucleic Acid. Nature 171, 737-738 (1953).

51. Seeman, N. C. Nucleic acid junctions and lattices. J. Theor. Biol. 99, 237-247 (1982).

52. Rothemund, P. W. K. Folding DNA to create nanoscale shapes and patterns. Nature 440, 297-302 (2006).

53. Allen, T. M. \& Cullis, P. R. Drug Delivery Systems: Entering the Mainstream. Science (80-. ). 303, (2004).

54. Hurtig, J., Gustafsson, B., Tokarz, M. \& Orwar, O. Electrophoretic transport in surfactant nanotube networks wired on microfabricated substrates. Anal. Chem. 78, 5281-5288 (2006).

55. Bao, Y., Qian, H. J., Lu, Z. Y. \& Cui, S. Revealing the Hydrophobicity of Natural Cellulose by Single-Molecule Experiments. Macromolecules 48, 3685-3690 (2015).

56. Nyström, G. et al. Self-assembled three-dimensional and compressible interdigitated thin-film supercapacitors and batteries. Nat. Commun. 6, (2015). 
57. Herland, A., Thomsson, D., Mirzov, O., Scheblykin, I. G. \& Inganäs, O. Decoration of amyloid fibrils with luminescent conjugated polymers. J. Mater. Chem. 18, 126-132 (2008).

58. Nilsson, K. P. R., Herland, A., Hammarström, P. \& Inganäs, O. Conjugated polyelectrolytes: conformation-sensitive optical probes for detection of amyloid fibril formation. Biochemistry 44, 3718-24 (2005).

59. Rizzo, A., Inganäs, O. \& Solin, N. Preparation of phosphorescent amyloid-like protein fibrils. Chem. - A Eur. J. 16, 4190-4195 (2010).

60. Rizzo, A., Solin, N., Lindgren, L. J., Andersson, M. R. \& Inganäs, O. White light with phosphorescent protein fibrils in OLEDs. Nano Lett. 10, 2225-30 (2010).

61. Viktor Andersson, B., Skoglund, C., Uvdal, K. \& Solin, N. Preparation of amyloidlike fibrils containing magnetic iron oxide nanoparticles: Effect of protein aggregation on proton relaxivity. Biochem. Biophys. Res. Commun. 419, 682-686 (2012).

62. Bäcklund, F. G. \& Solin, N. Tuning the aqueous self-assembly process of insulin by a hydrophobic additive. RSC Adv. 5, 92254-92262 (2015).

63. Herland, A., Björk, P., Hania, P. R., Scheblykin, I. G. \& Inganäs, O. Alignment of a conjugated polymer onto amyloid-like protein fibrils. Small 3, 318-325 (2007).

64. Wigenius, J., Andersson, M. R., Esbjörner, E. K. \& Westerlund, F. Interactions between a luminescent conjugated polyelectrolyte and amyloid fibrils investigated with flow linear dichroism spectroscopy. Biochem. Biophys. Res. Commun. 408, 115-119 (2011).

65. Bäcklund, F. G. et al. Conducting microhelices from self-assembly of protein fibrils. Soft Matter 13, (The Royal Society of Chemistry, 2017).

66. Loksztejn, A. \& Dzwolak, W. Vortex-Induced Formation of Insulin Amyloid Superstructures Probed by Time-Lapse Atomic Force Microscopy and Circular Dichroism Spectroscopy. J. Mol. Biol. 395, 643-655 (2010).

67. Gruziel, M., Dzwolak, W. \& Szymczak, P. Chirality inversions in self-assembly of fibrillar superstructures: a computational study. Soft Matter 9, 8005 (2013).

68. Dzwolak, W. \& Pecul, M. Chiral bias of amyloid fibrils revealed by the twisted conformation of Thioflavin T: An induced circular dichroism/DFT study. FEBS Lett. 579, 6601-6603 (2005).

69. Loksztejn, A. \& Dzwolak, W. Chiral Bifurcation in Aggregating Insulin: An Induced Circular Dichroism Study. J. Mol. Biol. 379, 9-16 (2008).

70. Niziol, J. et al. DNA-hexadecyltrimethyl ammonium chloride complex with enhanced thermostability as promising electronic and optoelectronic material. 
Journal of Materials Science: Materials in Electronics 28, 1-10 (2016).

71. Rujoiu, T. B. et al. Lasing in DNA-CTMA doped with Rhodamine 610 in butanol. Phys. Chem. Chem. Phys. 17, 13104-13111 (2015).

72. Reddy, M. S. P. \& Park, C. Bright luminescence from pure DNA-curcumin-based phosphors for bio hybrid light-emitting diodes. Sci. Rep. 6, 32306 (2016).

73. Lazar, C. A., Kajzar, F., Rau, I., Puntus, L. \& Manea, A.-M. Synthesis, linear and nonlinear optical properties of DNA-CTMA/europium (III) complex. Synth. Met. 221, 120-126 (2016).

74. Ouchen, F. et al. DNA-Conductive polymer blends for applications in Biopolymer based field effect transistors (FETs). Proc. SPIE 7040, 704009 (2008).

75. Yusoff, A. R. bin M., Kim, J., Jang, J. \& Nazeeruddin, M. K. New Horizons for Perovskite Solar Cells Employing DNA-CTMA as the Hole-Transporting Material. ChemSusChem 9, 1736-1742 (2016).

76. Sun, Q. et al. Highly efficient quantum-dot light-emitting diodes with DNA-CTMA as a combined hole-transporting and electron-blocking layer. ACS Nano 3, 737743 (2009).

77. Hirata, K. et al. Electroluminescence as a probe for elucidating electrical conductivity in a deoxyribonucleic acid-cetyltrimethylammonium lipid complex layer. Appl. Phys. Lett. 85, 1627-1629 (2004).

78. Agarwal, M., Lvov, Y. \& Varahramyan, K. Conductive wood microfibres for smart paper through layer-by-layer nanocoating. Nanotechnology 17, 5319-5325 (2006).

79. Moore, G. E. Cramming More Components onto Integrated Circuits. Electronics 114-117 (1965). 


\section{SUMMARY OF PAPERS}

\section{Paper I}

C. Müller, R. Jansson, A. Elfwing, G. Askarieh, R. Karlsson, M. Hamedi, A. Rising, J. Johansson, O. Inganäs and M. Hedhammar. Functionalisation of recombinant spider silk with conjugated polyelectrolytes. J. Mater. Chem. 21, 2909-2915 (2011)

In this paper we investigated if artificial spider silk ("spiber") would interact with conjugated molecules. The decoration procedure was investigated and it was found that elevated temperature, time and low $\mathrm{pH}$ was crucial for creating conducting material. The resulting wires exhibited conductance over several centimeters. The decoration procedure could be extended to the conjugated and fluorescent polymer PTAA (poly(thiophenic acid)).

\section{Paper II}

M. Hamedi, A. Elfwing, R. Gabrielsson and O. Inganäs. Electronic polymers and DNA self-assembled in nanowire transistors. Small, 9, 363-8 (2013)

In this paper we explored the possibility to create a PEDOT-S:DNA complex. Using divalent ions as charge bridges we were able to create a complex while retaining the conducting properties of PEDOT-S. The decoration process was followed by the quenching of a DNA intercalating dye (YOYO) by the metallic polymer. Due to the size of the DNA involved ( $\lambda$ DNA ) it was possible to stretch DNA-decorated strands across an electrode gap. In this fashion it was possible to measure conductivity and also to create a depletion mode electrochemical transistor.

\section{Paper III}

P. K. Johansson, D. Jullesson, A. Elfwing, S. I. Liin, C. Musumeci, E. Zeglio, F. Elinder, N. Solin and O. Inganäs, Electronic polymers in lipid membranes. Sci. Rep. 5, 11242 (2015)

In this paper we exploited the possibility to integrate the conductive polymer PEDOT-S into liposomes. Since PEDOT-S is water soluble it was necessary to create a new material which could be dissolved in organic solvents such as chloroform in order to integrate PEDOT-S into lipids. When PEDOT-S interacted with quarternary alkyl ammonium compounds it was possible to create a complex which was insoluble in aqueous solution but soluble in organic solvents. This complex was integrated into liposomes, resulting in $100 \mathrm{~nm}$ sized PEDOT-S:alkyl-ammonium:lipid liposomes . Using C-AFM it was possible to control that the conductivity of the PEDOT-S was still retained. Using QCM-D it was possible to follow the adhesion and release of the liposomes onto lipid bilayers. Electrophysiological measurements of PEDOT-S:liposomes on Xenopus oocytes showed a remarkable effect on ion-channels. 


\section{Paper IV}

F. G. Bäcklund, A. Elfwing, C. Musumeci, O. Inganäs and N. Solin, Conducting microhelices from self-assembly of protein fibrils. J. Mater. Chem. C, 3, 6499-6504 (2015)

In this paper we revisited the concept of creating PEDOT-S coated insulin amyloid fibrils. Using a novel mechanochemical technique for internalizing fluorescent dyes into amyloid fibers we were, for the first time, able to probe the interaction between a polyelectrolyte and amyloid fibrils. Using Förster Resonance Energy Transfer we were able to measure how the fluorescence from the internalized dye was quenched by the decoration of the metallic polymer. Furthermore the decoration procedure was optimized creating coated fibrils while removing any unbound PEDOT-S. Using conductive atomic force microscopy we were able to determine that the PEDOT-S was still conductive and the conductivity was restricted to the coated fibrils thus eliminating contribution from nonspecific binding.

\section{Paper V}

F. G. Bäcklund, A. Elfwing, C. Musumeci, F. N. Ajjan, V. Babenko, W. Dzwolak, O. Inganäs and N. Solin, Conducting microhelices from self-assembly of protein fibrils, Soft Matter, 13, 4412-4417 (2017)

In this paper we introduce helical superstructures based on insulin amyloid fibrils and their interaction with the conductive polymer PEDOT-S. Helically arranged conductive materials could possibly find their use in $\mathrm{THz}$ applications. We found that the conjugated polymer arranged itself onto, and probably also inside of, the helical structure in a helical fashion. The decoration procedure was investigated by Polarized Optical Microscopy (POM), Circular Dichroism (CD), scanning electron Microscopy (SEM) and conductive atomic force microscopy (C-AFM). The investigation yielded that the PEDOT-S arranged itself onto the helical structure. The amount of conjugated polymer attached to the structure was surprisingly high and the decoration did increase the stability of the structures. The increase in stability enabled the use of surface analytical techniques such as SEM and C-AFM and allowed the induced helicity to be retained after the decorated structures were deposited onto a solid surface

\section{Paper VI}

A. Elfwing, W. Cai, L. Ouyang, X. Liu, R. Gabrielsson and O. Inganäs.DNA based Hybrid Material for Interface Engineering in Polymer Solar Cells (manuscript)

In this paper we created a blend of a poly-anionic conjugated polymer PEDOT-S with a cationic surfactant and DNA. The resulting hybrid material lead to a change in the electronic properties of the PEDOT-S. The stable work function and excellent film forming properties of the material was utilized in organic photovoltaic devices where the blend was used as an electron transport layer. 


\section{Paper VII}

A. Elfwing A., C. Ponseca. L. Ouyang, A. Urbanovic, A. Kratkus, and O. Inganäs. Conducting helical structures from celery decorated with metallic conjugated polymer give $\mathrm{THz}$ resonances. (manuscript)

In this paper we expand the concept of dressing biomolecular scaffold with a conjugated polymer to cellulosic material. Helical shapes from celery were purified and selfassembled with PEDOT-S using a two-step process where the negative charge of cellulose was inverted by treatment with a polycation, PEI. This Layer-by-layer approach proved it was possible to create a cellulose/PEI/PEDOT-S complex with remarkable conducting properties. The helical arrangement of a conducting material onto a helical structure in the tens of micrometer range gave rise to well defined resonance in the $\mathrm{THz}$ regime. 


\section{ACKNOWLEDGEMENTS}

Financial support was provided by projects OPEN from the Strategic Research Foundation, Power Papers from the Knut and Alice Wallenbergs foundation (KAW) and a Wallenberg Scholar grant from KAW to Olle Inganäs.

\section{Ett stort tack till}

Min handledare Olle Inganäs - för stort tålamod, alla skratt och minst sagt högt svävande diskussioner. Men frågan återstår; vem hade du helst haft till bordet - Wittgenstein eller Popper?

Min biträdande handledare Anke Suska -du har alltid funnits där för mig.

Ett speciellt tack till Niclas Solin för all hjälp genom åren. Du har en bok för varje fråga.

To all co-authours and collaborators over the years - a special thanks to Wanzhu, Liangqi, Chiara, Fredrik, Shimelis, Zheng, Carlito, Luis, Roger, Julle, \& Patrik.

To all the members, past and present of the Biomolecular and Organic Electronics group. A big thanks to you all. A special thanks to Christian Müller and Mahiar Hamedi you inspired me - and you still do!

En av de bästa sakerna den här tiden har varit Forum Scientium - tack till alla nuvarande och gamla medlemmar. Utan Forum hade det den här tiden inte varit densamma. Ett särskilt tack till Stefan Klintström - Forums obestridde härförare- utan dig hade inte Forum varit vad det är.

Tack till alla administratörer på IFM; ni har hjälpt till med stort som med smått - särskilt tack till Anna-Maria.

Tack alla tekniker - Anders, Sven, Chun-Xia, Skalman, Roger, Peter - det är ni som håller den här skutan (IFM) flytande.

Kaffeklubben - utan kaffe inget liv. Gunnar, Staffan, Jens, Karin, Leffe, Katarina, Sara, Per, Robert S, Patricia, Judith, Robert G, Christoffer, Jonas C, Jonas B, Thomas, Möller, Pontus, Camilla, Lina, Linda, Kjersti, Joel, Lysholm. Nu förväntar jag mig en låång dikt - hexameter?

Epishine! $\mathrm{Nu}$ är jag färdig med forskandet. Nu drar vi igång på allvar. Tack för ert tålamod - Mattias, Jonas B, Emma och Thomas!

Experience-gänget: David, Linus, Lance, Andréas, Johannes och Hans. Tack för sköna avbrott i vardagen och alla hetsiga diskussioner - nästa gång möter vi våren i Baskien!

Jag vill tacka hela min familj som har stöttat mig genom åren. Mamma och Pappa, tack för att ni har lärt mig att tro på mig själv.

Nästan sist men inte minst; Isak och Irma - jag älskar er över allt annat på jorden.

Slutligen min älskade Ylva - jag förstår inte hur du står ut med mig men jag är djupt tacksam att du gör det. 


\section{Papers}

The papers associated with this thesis have been removed for copyright reasons. For more details about these see:

http://urn.kb.se/resolve?urn=urn:nbn:se:liu:diva-141675 